\title{
Spatial Selectivity and Binaural Responses in the Inferior Colliculus of the Great Horned Owl
}

\author{
Susan F. Volman and Masakazu Konishi \\ Division of Biology, California Institute of Technology, Pasadena, California 91125
}

In this study we have investigated the processing of auditory cues for sound localization in the great horned owl (Bubo virginianus). Previous studies have shown that the barn owl, whose ears are asymmetrically oriented in the vertical plane, has a 2-dimensional, topographic representation of auditory space in the external division of the inferior colliculus (ICX). As in the barn owl, the great horned owl's ICx is anatomically distinct and projects to the optic tectum. Neurons in ICx respond over only a small range of azimuths (mean $=32^{\circ}$ ), and azimuth is topographically mapped. In contrast to the barn owl, the great horned owl has bilaterally symmetrical ears and its receptive fields are not restricted in elevation.

The binaural cues available for sound localization were measured both with cochlear microphonic recordings and with a microphone attached to a probe tube in the auditory canal. Interaural time disparity (ITD) varied monotonically with azimuth. Interaural intensity differences (IID) also changed with azimuth, but the largest IIDs were less than $15 \mathrm{~dB}$, and the variation was not monotonic. Neither ITD nor IID varied systematically with changes in the vertical position of a sound source. We used dichotic stimulation to determine the sensitivity of ICx neurons to these binaural cues. Best ITD of ICX units was topographically mapped and strongly correlated with receptive-field azimuth. The width of ITD tuning curves, measured at $50 \%$ of the maximum response, averaged $72 \mu \mathrm{sec}$. All ICx neurons responded only to binaural stimulation and had nonmonotonic IID tuning curves. Best IID was weakly, but significantly, correlated with best ITD $(r=0.39, p<0.05)$. The IID tuning curves, however, were broad (mean $50 \%$ width $=24 \mathrm{~dB}$ ), and $67 \%$ of the units had best IIDs within $5 \mathrm{~dB}$ of $0 \mathrm{~dB}$ IID. ITD tuning was sensitive to variations in IID in the direction opposite to that expected for time-intensity trading, but the magnitude of this effect was only $1.5 \mu \mathrm{sec} / \mathrm{dB}$ IID.

We conclude that, in the great horned owl, the spatial selectivity of ICx neurons arises primarily from their ITD tun-

\footnotetext{
Received Oct. 31, 1988; revised Feb. 10, 1989; accepted Feb. 28, 1989.

We thank R. Adolphs, S. Esterly, I. Fujita, E. Knudsen, J. Olsen, and T. Takahashi for their comments on the manuscript, and $\mathrm{T}$. Takahashi, $\mathrm{H}$. Wagner, and C. E. Carr for their advice, assistance, and helpfil discussions throughout the work. We are also grateful to the following people: M. Zucker for artwork; Dr. D. E. M. Lawson for providing the primary antiserum for calbindin immunohistochemistry; and Drs. D. Van Essen and J. Allman, whose facilities we used for computer microscopy and 3-D reconstructions. This work was supported by NRSA Fellowship NS07714 (to S.F.V.) and NSF Grant BNS8411458 (to M.K.).

Correspondence should be addressed to Susan F. Volman, Division of Biology 216-76, California Institute of Technology, Pasadena, CA 91125.

Copyright (C) 1989 Society for Neuroscience $0270-6474 / 89 / 093083-14 \$ 02.00 / 0$
}

ing. Except for the absence of elevation selectivity and the narrow range of best IIDs, ICx in the great horned owl appears to be organized much the same as in the barn owl.

The ability to localize sound accurately is particularly well developed in nocturnal predators and in some animals with large heads like dogs and humans. Similar binaural localization cuesdifferences in the amplitude and arrival time of sounds-could in theory be available to all animals of the same size. In fact, the accuracy of localization also depends on specializations of the external ears, hearing range, and the precision with which binaural cues are processed neurally. Comparative behavioral studies of sound localization have been carried out on a variety of species (e.g., Heffner and Heffner, 1987, 1988), but extensive studies of the neural processing of binaural cues have been done in only a few species: barn owls, bats, and cats.

Barn owls use binaural cucs to localize sounds in 2 dimensions (Knudsen and Konishi, 1979; Moiseff and Konishi, 198 la; Moiseff, 1989a, b). Owing to the anatomy of the barn owl's head and ears, at frequencies above about $5 \mathrm{kHz}$, interaural differences in sound intensity vary primarily with the elevation of a sound source, whereas interaural time differences are correlated primarily with azimuth. As in all vertebrates, the ears are horizontally separated, and sound arrives first at the ear closer to the source. In contrast to those of most other animals, the barn owl's ears are also asymmetrically oriented in the vertical plane (Payne, 1971). For the higher frequencies, sounds from above the horizon are louder in the right ear, and sounds from below the horizon are louder at the left (Knudsen and Konishi, 1979; Coles and Guppy, 1988; Moiseff, 1989b).

The barn owl's auditory midbrain nucleus, the inferior colliculus (IC, also called MLD: nucleus mesencephalicus lateralis, pars dorsalis), has several anatomically distinct subdivisions (Knudsen, 1983). In the external subdivision (ICX), along the lateral margin of IC, there is a 2-dimensional map of auditory space in which the neurons have broad frequency tuning and spatially selective receptive fields that average $25^{\circ}$ in azimuth and $75^{\circ}$ in elevation (Knudsen and Konishi, 1978a, b). Within this space-mapped area, a neuron responds only to a specific combination of interaural time and amplitude differences (Moiseff and Konishi, 1981a; Takahashi et al., 1984). Spatially selective units have also been recorded in the ICx of 3 diurnal raptors (Calford et al., 1985). The receptive fields were, however, much broader than in the barn owl. In azimuth, the fields were limited only at the medial edge, and they were not limited in elevation. No clear topographic organization was found.

In mammals, interaural time and intensity cues are both used, over different frequency ranges, to determine azimuth (reviewed 
by Blauert, 1983; Hafter, 1984; Yin and Kuwada, 1984). In IC, topographic arrangements of spatial selectivity have been found in cats among low-frequency units sensitive to interaural time differences (Yin et al., 1983; Aitkin et al., 1985), and in bats among high-frequency units tuned to interaural amplitude differences (Fuzessery and Pollak, 1985; Wenstrup et al., 1986). In no mammal, however, has there been found a spatiotopic area in IC distinct from the tonotopic area; only at the level of superior colliculus does a topographic representation of auditory space appear (King and Palmer, 1983; Middlebrooks and Knudsen, 1984; Wong, 1984; King and Hutchings, 1987).

Among the owls, bilateral ear asymmetry is not unique to the barn owl; it appears to have evolved independently several times and is based on a variety of anatomical adaptations (Kelso, 1940; Norberg, 1977, 1978). In all forms, ear asymmetry in owls presumably improves auditory localization in the vertical plane (Pumphrey, 1948; Payne, 1971; Norberg, 1977). For a predator hunting from the air or from a perch, vertical discrimination is advantageous because it translates to distance along the ground. However, many owls, including the great horned owl, do not have asymmetrical ears. Great horned owls do not orient to sounds as readily as do barn owls, and they cannot be trained to fly to an auditory target in complete darkness (Payne, 1971). They are insensitive to frequencies above about $6-7 \mathrm{kHz}$ (Trainer, 1946) in contrast to barn owls, which hear well at over 10 $\mathrm{kHz}$ (Konishi, 1973). On the other hand, great horned owls have relatively large heads and correspondingly large interaural distances, which could enhance the binaural cues for auditory localization. We have recorded from this owl's IC with the aim of answering 2 questions: (1) Is the existence of a map of auditory space at the level of IC unique to owls with asymmetrical ears? (2) Are interaural cues used differently by an owl with symmetrical ears?

\section{Materials and Methods}

Data were collected from 13 nonreleasable great horned owls (Bubo virginianus) obtained as adults from raptor rehabilitation facilities in California. Each owl was anesthetized with intramuscular injections of ketamine hydrochloride $(16 \mathrm{mg} / \mathrm{kg} / \mathrm{hr}$, or as needed) and Valium $(0.7$ $\mathrm{mg} / \mathrm{kg} / \mathrm{hr}$ ), restrained in a leather jacket, and secured upright to a supporting post. The head was placed in a stereotaxic head holder so that a plane defined by the ear bars and the ventral surface of the palatine ridge was tilted $45^{\circ}$ down from horizontal. This head angle positioned the eyes looking approximately along the horizontal plane. A stainlesssteel head plate was cemented to the skull anterior to the interaural axis; at the intersection of this axis and the midline of the skull, a zero reference post was implanted. After the head holder was removed, a supporting rod attached to the head plate held the head in the correct orientation. A small hole was made in the skull, and the dura was kept moist with silicone grease throughout an experiment. A water-blanket heating pad was used to warm the animal. If a bird was to be used for subsequent recording sessions, the craniotomy was sealed with dental cement, a topical antibiotic (Neosporin, Burroughs Wellcome) was applied to the wound, and the scalp was sutured.

Unit recording. Glass-coated platinum-iridium microelectrodes of our own manufacture, or in a few experiments, parylene-coated tungsten electrodes (Micro Probe, Inc.), were positioned with respect to the zero post and advanced through the brain with a remote-controlled stepping motor. The IC was usually encountered at $2-6 \mathrm{~mm}$ posterior and 5-7 $\mathrm{mm}$ lateral to the zero position; its depth was $1.9-2.1 \mathrm{~cm}$ below the dural surface. Small electrolytic lesions were made on some penetrations to verify the electrode position. Extracellularly recorded action potentials were amplified and discriminated on the basis of their amplitudes. The times of occurrence of action potentials relative to a synchronizing pulse were stored by a PDP $11 / 40$ computer.

Stimuli. All experiments were conducted in sound-attenuating chambers (Industrial Acoustics Company); the chamber used for free-field experiments was anechoic as well. The sound-delivery systems used in this study were essentially the same as those used in previous studies on barn owls (Knudsen and Konishi, 1978a; Moiseff and Konishi, 1981a; Takahashi and Konishi, 1986). Auditory stimuli consisted of $100 \mathrm{msec}$ noise or tone bursts with $5 \mathrm{msec}$ rise and fall times presented 5-10 times at $1.5 / \mathrm{sec}$. The broadband noise was constant to within $10 \mathrm{~dB}$ between 2500 and $7000 \mathrm{~Hz}$. At $2000 \mathrm{~Hz}$ the amplitude was $14 \mathrm{~dB}$ less than the maximum at $6500 \mathrm{~Hz}$. The free-field speaker, mounted on a semicircular track, could be positioned anywhere on a sphere of radius $1 \mathrm{~m}$ around the owl except for a $100^{\circ}$ sector, where the supporting post interfered, from $80^{\circ}$ below the horizon in front of the owl and extending through the lower quadrant behind the owl (Knudsen and Konishi, 1978b). For dichotic stimulation, we used the calibrated earphones described by Takahashi and Konishi (1986). Intensity and timing of sound at the 2 ears could be controlled independently by manual or computer-controlled attenuators and a time shifter (Moiseff and Konishi, 1981a). The earphones were held in place by an annular plug molded from earmold impression material (All American Mold Laboratories). These plugs fit snugly into the external auditory meatus and were secured simply by the pressure of the skin fold surrounding the ear opening. Both plug and earphone could be removed and reinserted without disturbing the recording electrode, enabling us to stimulate single neurons both in free field and dichotically.

Cochlear microphonic and probe tube measurements. In 2 owls, differential cochlear microphonic (CM) electrodes were implanted bilaterally. Owls were anesthetized, and a small window was made on the posterior-lateral region of the skull exposing the middle-ear cavity. The cut end of a Teflon-coated silver wire $(0.005$ inch diameter) was inserted into a hole in the bone over the scala vestibuli. A second insulated silver wire, the tip of which had been heated to form a small ball, was placed in contact with the round window. Both electrodes were cemented to the skull, the hole was closed with dental cement, and the incision sutured with the electrodes leading out through the skin.

The stimuli and methods for calculating interaural time and intensity from the CM were similar to those used by Moiseff (1989b), and we will describe them only briefly here. Continuous tones or broadband noise were broadcast from positions $10^{\circ}$ or $20^{\circ}$ apart along the horizontal and vertical meridians. Continuous sounds, rather than bursts, were used so that the sampled signals would be of uniform amplitude. The differential CM signals were amplified and recorded on separate channels of a digital spectrum analyzer (Data Precision, D-6000). A fast Fourier transform (FFT) was computed on each stored waveform using a haming filter. In the second owl, each pair of CM electrodes was calibrated separately with tones $0.5 \mathrm{kHz}$ apart from 2.5 to $4.5 \mathrm{kHz}$ and with noise. The amplitude component of the FFT for tones was recorded at 4 different sound levels, $10 \mathrm{~dB}$ apart. For noise, the RMS values over $1-10 \mathrm{kHz}$ were used. In the first owl we did not calibrate over a large enough range of sound levels, so amplitude data from this owl were not used. Interaural intensity was calculated by determining the sound level at each ear from its calibration curve and then subtracting the two values.

Interaural time difference was calculated at each speaker position by the following procedure: the phase spectrum of the CM response to noise at one ear was subtracted from the phase spectrum of the other ear. This phase-difference spectrum was linear between about 1.5 and $6 \mathrm{kHz}$. At 8-10 frequencies in this range, we measured the phase difference, used linear regression to obtain the slope (in $\mathrm{deg} / \mathrm{cycles} / \mathrm{sec}$ ), and converted to time by dividing by $360 \mathrm{deg} / \mathrm{cycle}$.

In one owl, a probe tube (inside diameter, $1 \mathrm{~mm}$; length, $25 \mathrm{~mm}$ ) attached to a $1 / 2$ inch calibrated microphone (Bruel and Kjaer) was inserted into the external auditory meatus through a small hole drilled in the skull behind the right ear. The probe-tube opening was positioned near the tympanum to measure the amplitude of sounds presented from various positions.

Histology and anatomy. To recover marking lesions and reconstruct the IC, the owls were overdosed with Nembutal and perfused transcardially with $0.9 \%$ saline followed by $10 \%$ formal-saline. Brains were then blocked parallel to the electrode penetrations, postfixed in $10 \%$ formalin and $30 \%$ sucrose, cut transversely in $30 \mu \mathrm{m}$ frozen sections, mounted, stained with cresyl violet, and drawn with the aid of a camera lucida. A 3-dimensional computer reconstruction (Boulder HVEM 3-D Reconstruction Program) of one IC was made from these drawings and rotated for a horizontal view of the nucleus. Alternate sections from 3 owls were used for immunohistochemical staining with an antibody to calbindin; they were processed by the method used on barn owls by Takahashi et al. (1987). 

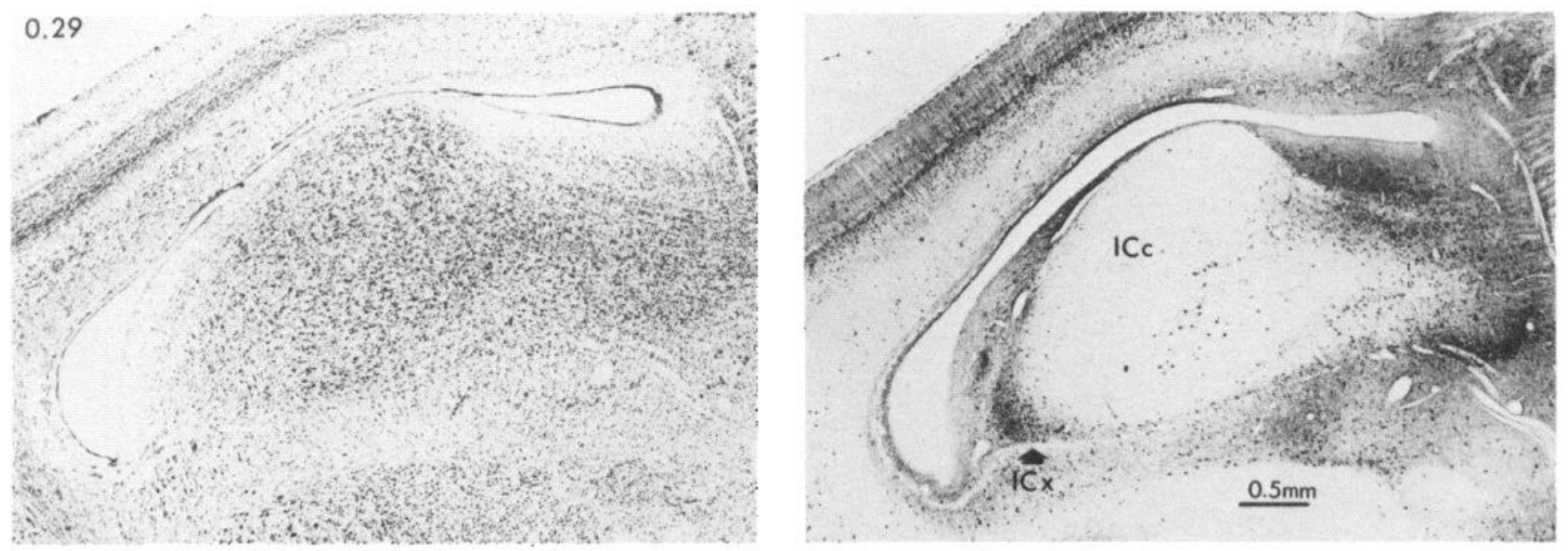

Figure 1. Transverse sections through the inferior colliculus (IC). IC is the large nucleus below the ventricle and is surrounded dorsally (up) and laterally $(l e f t)$ by the optic tectum. Left, Section stained with cresyl violet showing large, darkly stained cells in ICc grading into smaller cells at the lateral margin (ICx). Number at upper left is the fractional distance of this section from the caudal pole of IC. Right, Section adjacent to that at left stained for immunoreactivity to calbindin. ICx is visible as the area of darkly stained cells and neuropil lateral in the nucleus. Some large cells in ICc are also stained.

Retrograde tracers were injected into the optic tecta of 3 owls to label neurons in IC. In one owl we used fluorescent latex microspheres (Luma Fluor; Katz et al., 1984), and in 2 others, HRP. For the first method, we first recorded with a metal electrode and located an appropriate injection site in the optic tectum by crudely mapping the visual receptive fields. A glass micropipette ( $40 \mu \mathrm{m}$ i.d. at the tip), mounted onto a $1 \mu \mathrm{l}$ Hamilton microsyringe, was then used to inject a volume of $0.5 \mu \mathrm{l}(1:$ 1 dilution) at the stereotaxic position previously mapped. After $12 \mathrm{~d}$, the brain was processed as described above for cresyl-violet staining, except that unstained sections were viewed with fluorescence illumination and the positions of labeled cells were plotted on a computer microscope system. Alternate sections were stained with cresyl violet and drawn using a camera lucida. These drawings were superimposed on the computer plots to determine the location of the labeled cells. HRP (5-10\% dissolved in Tris-buffered saline, $\mathrm{pH} \mathrm{8.3)} \mathrm{was} \mathrm{injected}$ iontophoretically ( $+2-3 \mu \mathrm{A}$ DC current, $5 \mathrm{sec}$ on, $5 \mathrm{sec}$ off, for $20 \mathrm{~min}$ ) from a glass micropipette $(20 \mu \mathrm{m}$ inner diameter). With these electrodes, it was possible to confirm the electrode position by neuronal responses to visual stimuli in the tectum. After $2 \mathrm{~d}$, the birds were given an overdose of Nembutal, exsanguinated with saline, and fixed by perfusion with a mixture of $1 \%$ paraformaldehyde and $1.25 \%$ glutaraldehyde in phosphate buffer $(0.1 \mathrm{M}, \mathrm{pH} 7.4)$, followed by ice-cold $10 \%$ buffered sucrose. The brains were blocked, removed, and infiltrated with $30 \%$ sucrose, and $30 \mu \mathrm{m}$ frozen sections were collected in ice-cold buffer. Sections were processed for HRP histochemistry using tetramethyl benzidine as the chromogen (Mesulam, 1978) and counterstained with neutral red.

Terminology and conventions. The subdivisions of IC (ICc and ICx) are designated by the nomenclature of Knudsen (1983). Positive receptive-field azimuths refer to positions to the right of the midsaggital plane, and negative azimuths are to the left. Positive elevations are those above the horizontal meridian. Positive interaural time and sound level differences refer to sounds that are respectively leading or louder in the right ear. We continue here the long-standing tradition of using the abbreviation IID (interaural intensity difference) for what are actually interaural sound pressure differences. Peak, or best, interaural time disparity (ITD) and IID were calculated as weighted means of the ITD and IID tuning curves by the formula (given for ITD only):

$$
\text { Best ITD }=\sum_{i=1}^{n}\left(R_{i} \times \mathrm{ITD}_{i}\right) / \sum_{i=1}^{n} R_{i}
$$

where $R_{i}$ is the number of action potentials at the $i$ th ITD and $n$ is the number of sample ITDs.

\section{Results}

\section{Anatomy}

In the great horned owl, as in other birds, IC is a large nucleus surrounded by the optic tectum (Fig. 1). The mean rostrocaudal extent of IC was $4.0 \pm 0.4 \mathrm{~mm}$ ( $n=9$ nuclei in 7 birds). In transverse sections stained for Nissl substance, we could discern a triangular region of small cells along the lateral margin and rostral pole of IC (Fig. 1, left). This area, the external nucleus (ICx), was clearly different from the central, large-celled subdivision (ICc), although the border between the 2 areas was not sharp. These subdivisions were also visible in sections stained for calbindin immunohistochemistry (Fig. 1, right).

Fluorescent latex microspheres, or "beads" (Fig. 2), and HRP both indicated that there is a projection from ICx to the optic tectum. To position the injections of these retrograde tracers in the tectum, we first mapped the visual receptive fields. The injections were aimed at the intermediate and deep layers of the tectum in areas where the visual receptive fields were near the horizontal meridian. In one owl, beads were injected where the visual fields were about $15^{\circ}$ from the vertical meridian. This injection labeled cells in IC confined to ICx. Sections with 620 labeled cells spanned $0.4 \mathrm{~mm}(10 \%)$ of the rostrocaudal extent of the nucleus, and one or more labeled cells were found over about $0.9 \mathrm{~mm}(22 \%)$. The filled cells were found at all dorsoventral positions and were centered at $64 \%$ of the distance from the caudal to the rostral pole of IC. In a second owl, an HRP injection was made in the tectum where the visual fields were about $30^{\circ}$ from the midline. This injection labeled only $1-2$ cells per section over $0.4 \mathrm{~mm}$ of ICx, centered at $40 \%$ of the distance from the caudal pole of IC. No labeled cells were found in IC after a smaller HRP injection in a third owl was placed where the visual fields were $30-40^{\circ}$ from the midline.

With either tracer, the cells in ICx were only lightly labeled. In contrast, in all cases there was a restricted band of densely labeled cells in the parvocellular division of nucleus isthmi. When there were labeled cells in ICx, the band in isthmi appeared in approximately the same sections (Fig. 2). 
Figure 2. Reconstruction of injection site and cells labeled from the optic tectum (OT) after injection of rhodamineconjugated latex microspheres ("beads"). Numbers above the sections are the fractional distance from the caudal pole of IC. In the section at left, the injection site is stippled and shown in relation to the layers of OT. The tectal layers were grouped into superficial $(S)$, intermediate $(I)$, and deep $(D)$ in the same way as were those in the barn owl (Knudsen and Knudsen, 1983), based on the layers defined by Ramón y Cajal (1972). In the section on the right, all bead-labeled cells in IC are marked; only $20 \%$ of the labeled cells are shown for the band in nucleus isthmi parvocellularis $(I P)$, although the extent of the band is accurate. $I M$, nucleus isthmi magnocellularis; ICs, superficial subdivision of the inferior colliculus (Knudsen, 1983); BIC, brachium of the inferior colliculus.

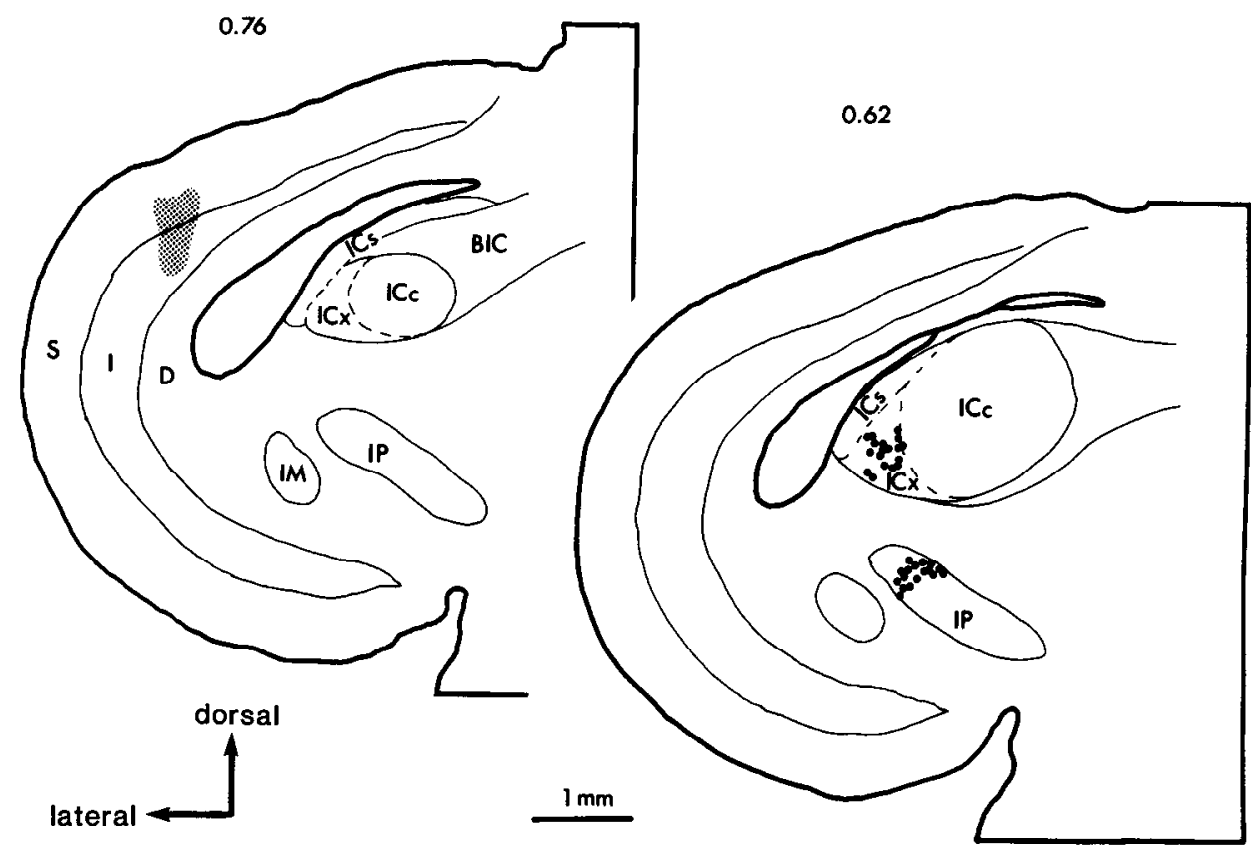

There is some suggestion that the connections to tectum are topographic because the more caudal injection in the tectum labeled cells was more caudal in ICx. Since each injection labeled at least $10 \%$ of the rostrocaudal extent of $\mathrm{IC}$, fibers from $\mathrm{ICx}$ may spread out and also overlap somewhat in the tectum.

\section{Spatial receptive fields}

The response properties of neurons in IC were recorded in 9 hemispheres of 7 owls using a movable, free-field speaker. Spatial receptive fields were plotted with noise bursts at $10 \mathrm{~dB}$ above threshold (Fig. 3), and for some units they were also replotted using higher-intensity noise bursts and tone bursts of various frequencies (Figs. 4 and 5). Within IC as a whole, the units had a variety of receptive field types. Some units responded over only a limited range of spatial positions, whereas the response of others was not dependent on position. Intermediate types responded to sounds in one entire hemifield or had several excitatory areas. The nonselective and intermediate types were found in the ICc, which was tonotopically organized: low frequencies $(500-700 \mathrm{~Hz})$ were encountered dorsally, and the highest frequencies, represented ventrally, were just over $6 \mathrm{kHz}$. Neurons with nonselective and intermediate receptive fields were not studied systematically.

A space-specified neuron, by our definition, had a receptive field with both clear medial and lateral boundaries (Fig. 3). These cells were found near the border between the central and external subdivisions of the nucleus and within ICx. Most spacespecific units had little or no spontaneous activity. They responded phasically, and at $10 \mathrm{~dB}$ above threshold the peak response of 63 single units averaged only 5.3 action potentials during the $100 \mathrm{msec}$ noise burst. The widths of the receptive fields along the horizontal meridian ranged from $15^{\circ}$ to $52^{\circ}$ (mean width for 58 single units $=32^{\circ} \pm 9^{\circ}$ ).

Every space-specific unit tested responded at all elevations from $80^{\circ}$ below to $80^{\circ}$ above the horizontal meridian, although the responses at $+80^{\circ}$ and $-80^{\circ}$ were usually less than those in the center. For 2 units, we moved the speaker beyond the $90^{\circ}$ overhead position until it reached the horizontal plane behind the owl's head. They both responded over this entire range of elevations within a narrow range of azimuths. Receptive fields with centers more than about $15^{\circ}$ from the vertical meridian tended to curve inward at the top and sometimes at the bottom (Fig. 3). Because of this curvature, we had to examine a range of azimuths at each elevation to quantify the responses. This was done for 14 single units and 1 cluster of 2-4 units. The best responses at $80^{\circ}$ above and below the horizontal meridian averaged $38 \%$ less than the maximum responses. Nine units responded with more than $50 \%$ of the maximum response over the entire $160^{\circ}$ range $\left(-80^{\circ}\right.$ to $\left.+80^{\circ}\right)$. For 5 units, the response fell below the $50 \%$ level at $-80^{\circ}$ but not at $-60^{\circ}$ nor at $+80^{\circ}$. The one multiunit recording was the most restricted, responding above the $50 \%$ level from $-80^{\circ}$ to only $+40^{\circ}$.

One test of whether a neuron has a truly specific spatial response, as compared with merely responding better at some locations, is to see if it will respond over a much broader range to louder sounds. The borders of the receptive fields of some ICx units ( 2 out of 5 tested quantitatively) did not change appreciably even when the stimulus was $30 \mathrm{~dB}$ above threshold (Fig. $4 A$ ). Other units ( 3 of 5 ) expanded by a maximum of $10^{\circ}$ (Fig. 4B).

Most space-specific units responded less well to tones than to noise. Individual neurons usually responded over a broad frequency range centered between 3 and $5 \mathrm{kHz}$ (Fig. $5 A$ ). When the response to tones was reliable enough to plot receptive fields, these were essentially identical to those plotted with noise stimuli, except that secondary fields often appeared at other locations. The positions of these fields moved systematically as a function of frequency (Fig. $5 B$ ).

In 6 hemispheres, we were able to sample most of the rostrocaudal extent of $\mathrm{ICx}$ in a single recording session. Within a vertical electrode penetration, the centers of receptive fields did not vary by more than $6^{\circ}$. Along the rostrocaudal axis, however, space-specific neurons were systematically arranged to create a map of auditory azimuth (Figs. 6, 7). The most caudally recorded units had receptive fields centered at $45^{\circ}$ contralateral. Anterior-lateral in $\mathrm{ICx}$, the receptive fields were directly in front 


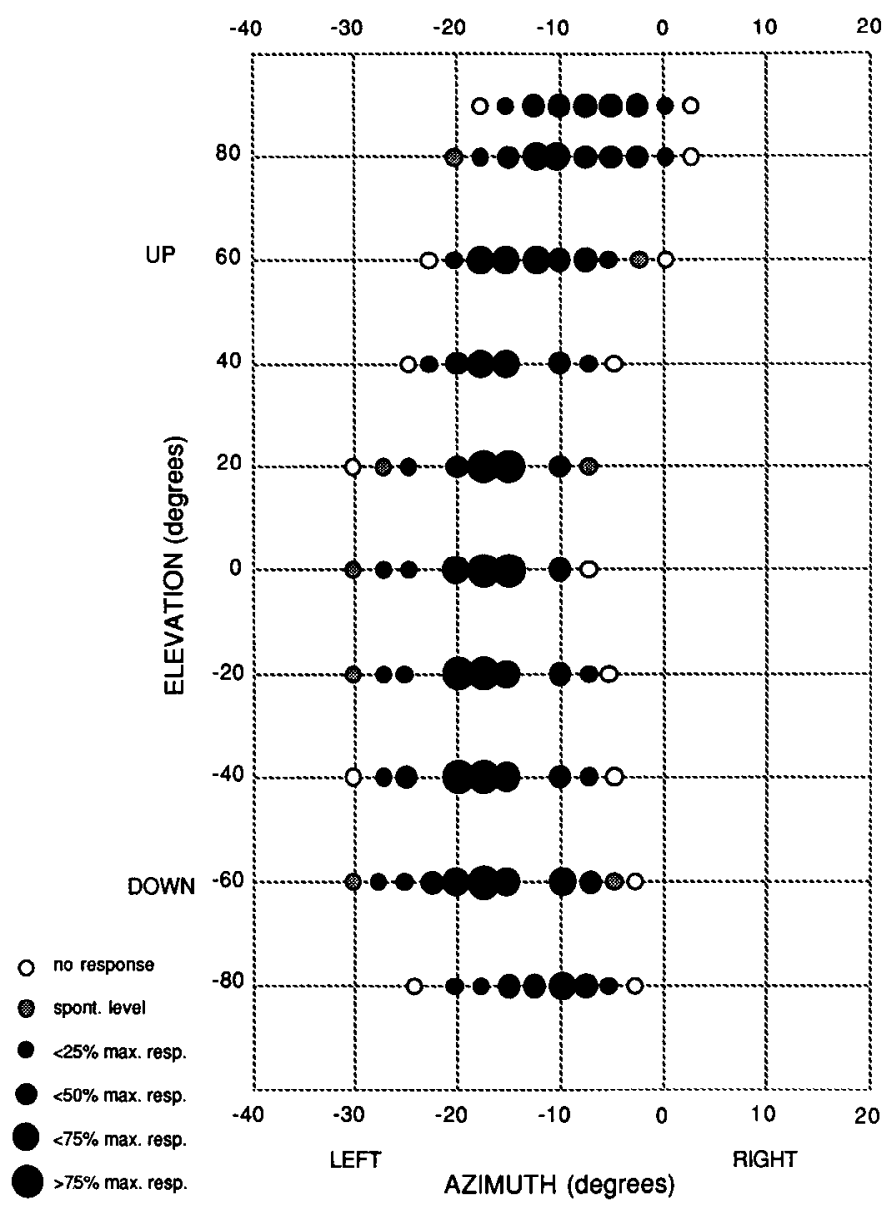

Figure 3. Receptive field of a neuron recorded in $\mathrm{ICx}$ on the right side of the brain. Speaker locations are plotted in horizontal polar coordinates. The stimulus was 5 presentations of a $100 \mathrm{msec}$ broad-band noise at $10 \mathrm{~dB}$ above threshold. The filled circles indicate the size of the response as shown in the legend. The mean maximum response was 5.4 action potentials/stimulus presentation. Mean spontaneous level as $0.2 \mathrm{APs} / \mathrm{stimulus}$ presentation. The open circles mark locations where the cell did not fire during the 5 presentations; because the spontaneous level was so low, these do not necessarily indicate inhibitory responses. of the owl. More medially, where ICx wraps around the anterior pole of ICc, fields were centered slightly ipsilaterally. The most ipsilateral field mapped was centered at $9^{\circ}$ ipsilateral. The range of space covered in ICx may actually be somewhat greater than about $55^{\circ}$ because the nucleus is very thin and narrow at the posterolateral and anteromedial extremes, and it is therefore more difficult to record from. No part of the azimuthal range from which we recorded appeared to have a greatly expanded representation in IC (Fig. 7).

From these experiments with free-field stimuli, it was clear that the great horned owl has a space map within ICx. Neurons here are selective for the azimuth, but not the elevation, of sound sources. The systematic displacement of secondary fields when tonal stimuli were used suggested that ITDs were the cue for azimuth. That is, these fields most likely result from the phase ambiguity inherent in tonal stimuli with periods shorter than the maximum intcraural time difference (see below).

\section{Measurement of interaural time and intensity disparities}

For any animal with 2 ears, both interaural time and intensity may vary as a function of the position of a sound source. The magnitude of ITD depends on the difference in the lengths of the sound paths to the 2 ears. IID depend on the ears' relative directionalities, which vary with frequency.

We measured ITD and IID at the ears of 2 owls by recording $\mathrm{CM}$ potentials. ITDs were calculated for noise bursts in both owls and for a $3 \mathrm{kHz}$ tone in one of them (Fig. 8). These ITDs, from $80^{\circ}$ left to $80^{\circ}$ right, were fit by linear-regression analysis by the equation:

$$
\text { ITD }=3.64 * \text { azimuth }-4.1, \quad r^{2}=0.95
$$

Directly in front of the owl, ITD did not change with elevation. We also tested ITD at various elevations at $30^{\circ}$ azimuth. ITD increased both above and below the horizon. At elevations of $+20^{\circ}$ and $+40^{\circ}$, ITD was $9 \mu \mathrm{sec}$ greater than at $0^{\circ}$ elevation; at $+60^{\circ}$ elevation, it was $18 \mu \mathrm{sec}$ greater; and at $+80^{\circ}, 42 \mu \mathrm{sec}$. Below $0^{\circ}$ elevation, ITD increased less, reaching only $17 \mu \mathrm{sec}$ at $-80^{\circ}$. These shifts, corresponding to nearly $12^{\circ}$ azimuth at $+80^{\circ}$ elevation, are consistent with the tendency of receptive fields to curve inward at extreme elevations (Fig. 3). Since the
A

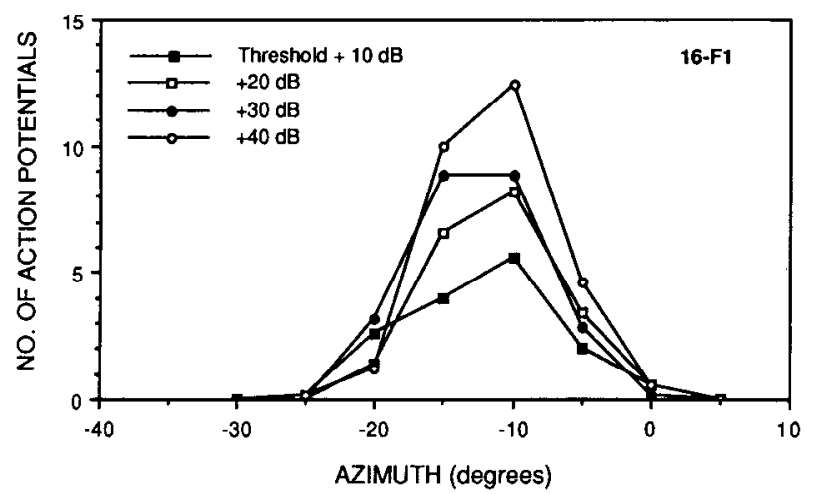

B

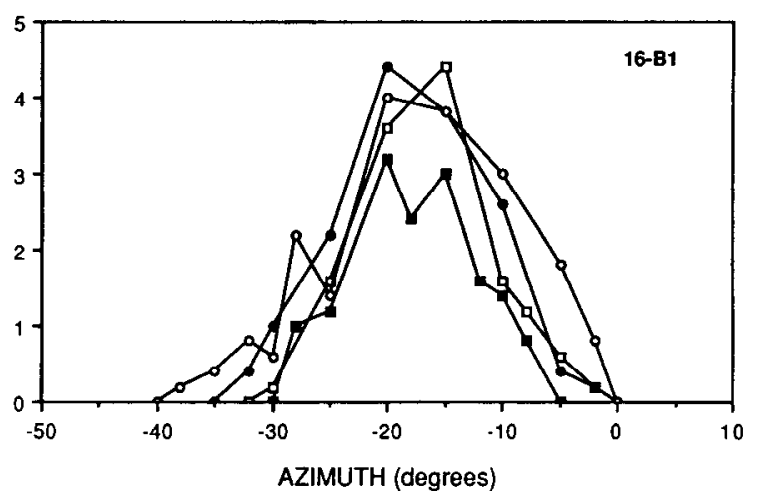

Figure 4. Effect of intensity on the azimuth of receptive fields. For unit 16-F1 $(A)$, receptive-field azimuth was essentially unaffected by increasing the stimulus level, but the response at the center of the field more than doubled. In contrast, unit 16-B1 $(B)$ responded over a wider range to louder sounds, but its firing rate remained low. The legend at left applies to both units. 


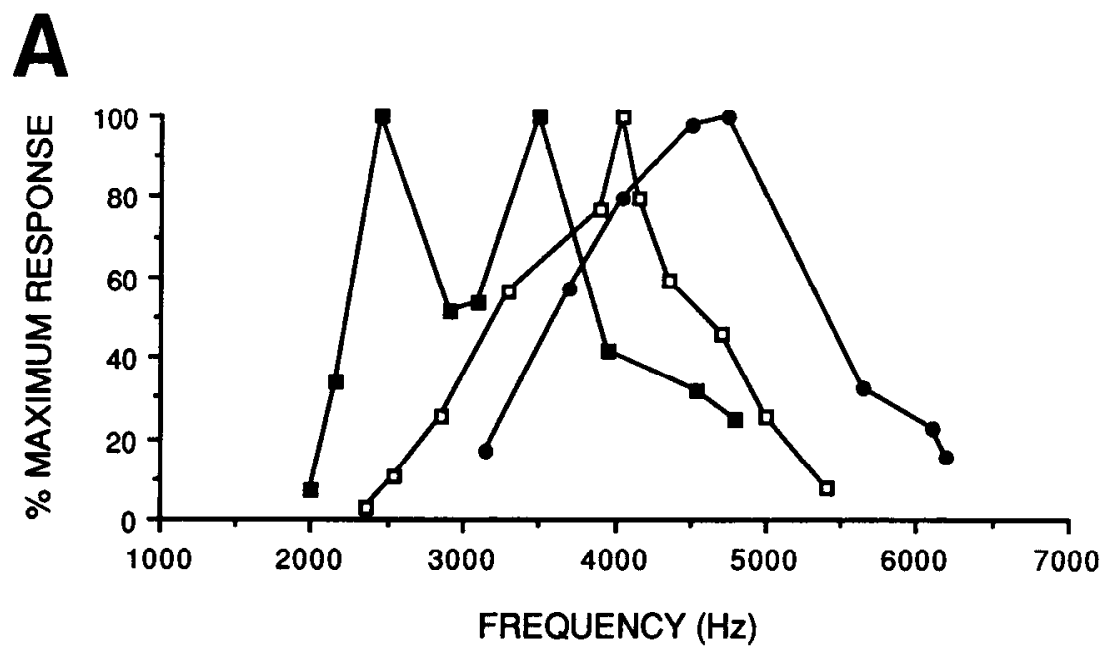

Figure 5. Frequency tuning and spatial response to tones. $A$, Representative frequency tuning curves of $3 \mathrm{ICx}$ neurons. It was not unusual for these units to respond maximally to 2 widely separated frequencies. $B$, Spatial response of a single unit to noise and tones. To noise at $10 \mathrm{~dB}$ above threshold, the unit responded at greater than the $50 \%$ level only near its peak at $17^{\circ}$ left. The tones, at $15 \mathrm{~dB}$ above threshold, elicited large responses at other positions as well. The higher-intensity tones were necessary in order to elicit maximal responses greater than 1-2 action potentials. At progressively higher frequencies, the extra peaks moved closer to the main peak.
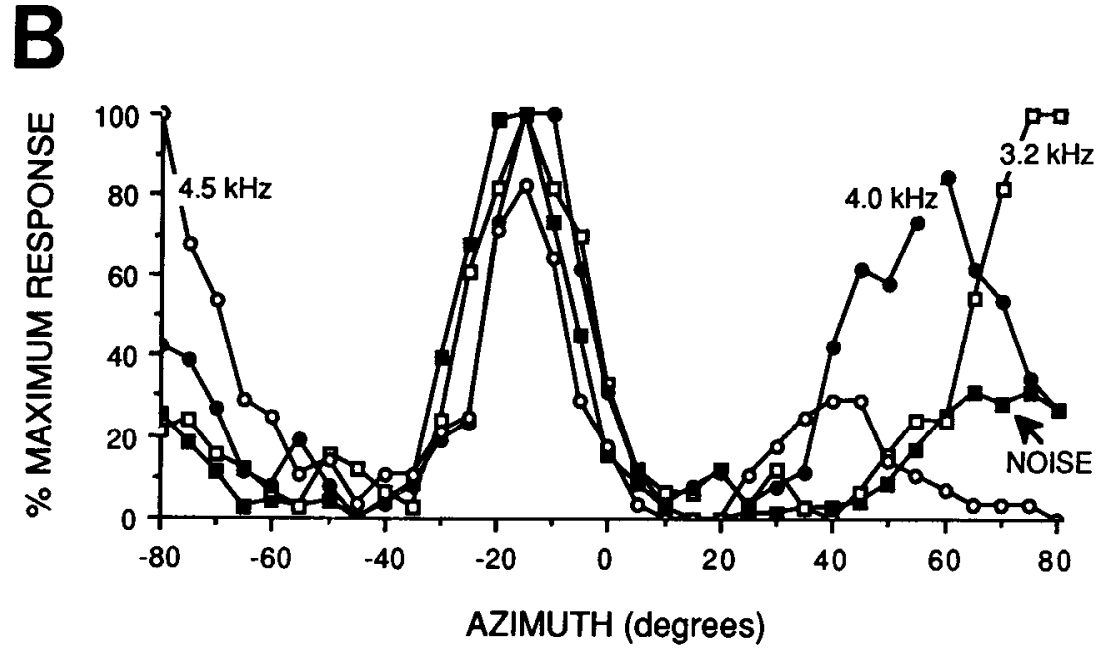

owl's skull is not spherical, it is not surprising that the relative lengths of the sound paths to the ears varies with elevation.

Azimuthal IID was measured with 3 and $4 \mathrm{kHz}$ tones and noise at positions $360^{\circ}$ around the horizon, although only those data from $100^{\circ}$ left to $100^{\circ}$ right are shown (Fig. $9 \mathrm{~A}$ ). Frequencies above $4 \mathrm{kHz}$ were not tested because the signal-to-noise ratio of the CM electrodes was too poor. All IIDs were calculated relative to the value at $0^{\circ}$ azimuth and clcvation. For the tonal stimuli, FFTs of the CM signal from each ear were computed, and IID was calculated from the amplitude of the spectral component corresponding to the stimulus frequency. For noise, we used the RMS value of the signal calculated over $1-10 \mathrm{kHz}$. The largest IID, at $60^{\circ}$ left for the $4 \mathrm{kHz}$ tone, was only $12.5 \mathrm{~dB}$. At this frequency, the IIDs between $60^{\circ}$ left and $60^{\circ}$ right were essentially linear with azimuth. They could be fit by the equation:

$$
\text { IID }=0.14 * \text { azimuth }-3.1 \quad r^{2}=0.94
$$

The $y$ offset is large because all IIDs were calculated relative to the value at $0^{\circ}$, and this IID deviates most from the regression line. If we assume that azimuthal IID is actually symmetrical around $0^{\circ}$, then from the equation above, the IIDs at left and right $60^{\circ}$ would be $8.4 \mathrm{~dB}$.
We also measured IID at $0^{\circ}$ azimuth for elevations from $80^{\circ}$ below to $90^{\circ}$ above the horizontal meridian (Fig. $9 B$ ). IID varied by no more than $4 \mathrm{~dB}$ at any elevation.

The small binaural amplitude disparities indicate that the monaural directionalities of the 2 ears are similar and that the great horned owl's head does not effectively shadow sounds in the $3-4 \mathrm{kHz}$ range. Along the horizontal meridian, each ear was most sensitive to an ipsilateral sound source $20^{\circ}-60^{\circ}$ from the midline, and least sensitive at $120^{\circ}-160^{\circ}$ contralaterally behind the head. For the $4 \mathrm{kHz}$ tone, the greatest increase from the amplitude at $0^{\circ}$ was $4.5 \mathrm{~dB}$ (at $20^{\circ}-60^{\circ}$ ipsilateral, left ear), and the greatest decrease was $17 \mathrm{~dB}$ (at $140^{\circ}$ contralateral, right ear). In the vertical plane, the amplitude in both ears was maximal between $60^{\circ}$ down and $30^{\circ}$ up. At $90^{\circ}$ up, the amplitude of the $4 \mathrm{kHz}$ tone in the left ear was $3 \mathrm{~dB}$ less than at $0^{\circ}$ and amplitude in the right ear was decreased by $4.5 \mathrm{~dB}$. These monaural reductions are consistent with the smaller responses of $\mathrm{ICx}$ neurons at large elevations.

We also measured monaural directionality with a probe microphone in the right ear of the same owl whose CM data are shown in Figure 9, $A, B$. These data (Fig. 9, $C, D$ ) were essentially the same as those from the $\mathrm{CM}$ recordings. The stimuli were equivalent to $74 \mathrm{~dB}$ outside the owl's head. When the probe 


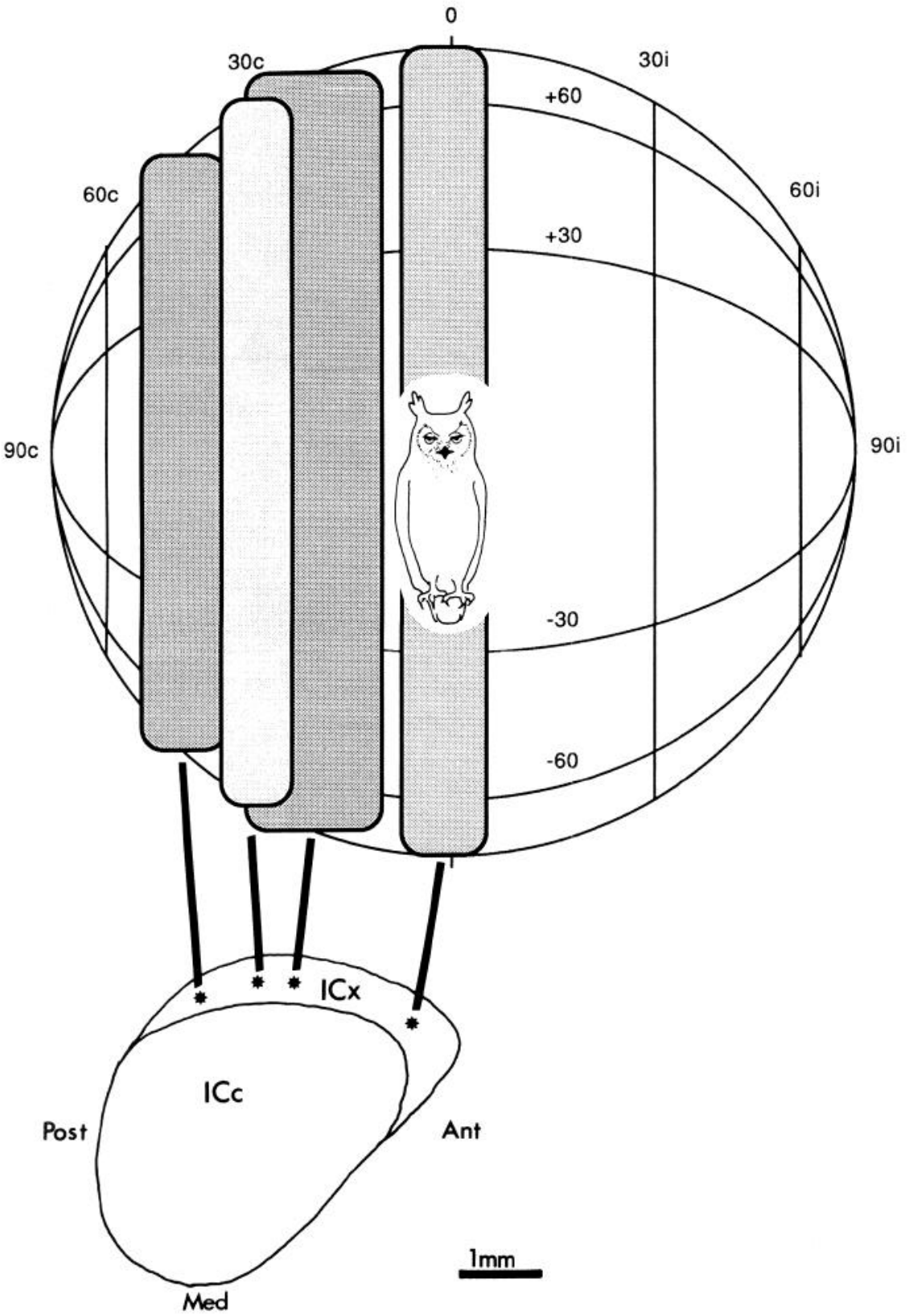

Figure 6. Reconstructed horizontal view of IC on the left side of the brain showing the relationship of a unit's receptive field to its position in the nucleus. Top, Receptive field of one unit from each of 4 penetrations. The fields are shown as rectangles with widths equal to the range, at the horizontal meridian, of at least $75 \%$ maximum response. All units responded throughout the vertical range at greater than $50 \%$ of their maximum firing level. Bottom, The horizontal view of IC was reconstructed from coronal sections using a 3 -D reconstruction program. The 4 penetrations were each marked with an electrolytic lesion, shown as an asterisk in ICx. tube was in the ear, the sound was amplified by about $10 \mathrm{~dB}$ at the best positions for both tones and noise.

The measurements in the auditory periphery suggest that ITD, which varied linearly with azimuth at the rate of $3.6 \mu \mathrm{sec} / \mathrm{deg}$, is the most likely cue for azimuthal positions. IID also varied linearly for most frontal positions, but over a range of only 17 $\mathrm{dB}$. The small deviations of both ITD and IID for positions in the vertical plane indicate that neither is likely to be a suitable cue for the elevation of a sound source.

\section{Dichotic stimulation}

Stimuli presented through earphones were used to measure the sensitivity of IC neurons to ITD, IID, and frequency. We first sought to determine if ITD tuning was mapped in ICx and if a neuron's ITD tuning could predict its receptive field.

In vertical penetrations through ICx, best ITD was constant to within $30 \mu \mathrm{sec}$. Posterior in ICx, neurons were tuned to ITDs of greater than $200 \mu \mathrm{sec}$, whereas anterior in the nucleus the most effective ITDs were near $0 \mu \mathrm{sec}$. Furthermore, best ITD changed monotonically along the length of the nucleus (Fig. 10). Thus, along with the free-field space map, there is a map of ITD.

To determine directly whether these ITDs correlated with spatial position, we recorded at single sites with dichotic and free-field stimulation (Fig. 11). Single units were isolated in ICx and their ITD tuning was recorded. Subsequently, the earphones were removed and the owl, with the electrode in place, was transferred to the anechoic room, where the spatial receptive field was plotted with free-field stimuli. The electrode was then advanced to isolate a second unit, and we recorded under the 2 conditions in reverse order. If the isolation deteriorated in transfer, multiunit data were collected without moving the elec- 


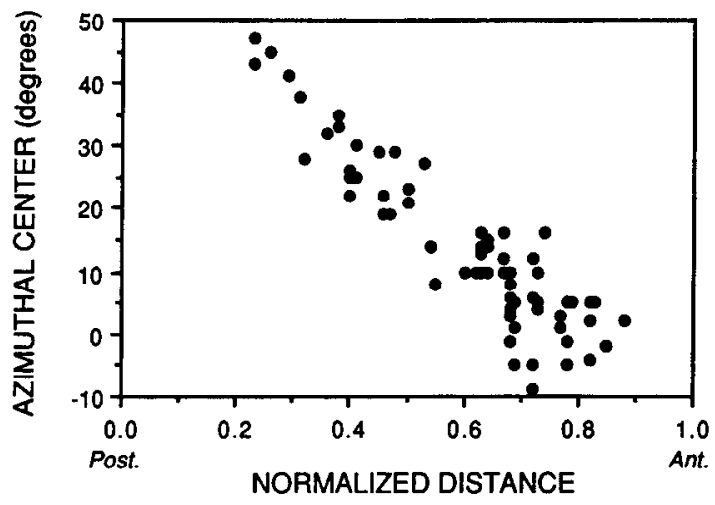

Figure 7. Relationship between the azimuth of receptive fields and position in IC. The data are from 68 units from 45 penetrations in 7 hemispheres ( 3 left, 4 right). Positive field locations are contralateral, negative are ipsilateral. We assessed the receptive field center of 14 units by ear; for the rest we calculated best azimuth from quantitative data like those shown in Figure 3. The normalized position of each penetration, relative to the posterior and anterior poles of IC, was calculated from the position of marker lesions. For penetrations without lesions, position was calculated from their stereotaxic coordinates relative to the closest penetration with a lesion and adjusted for shrinkage.

trode further. The peaks of the ITD tuning curves and the azimuthal positions of receptive-field centers were tightly correlated $\left(r^{2}=0.97\right)$ and linearly related by the equation

$$
\text { best ITD }=3.88 * \text { best azimuth }-8.27
$$

This scaling factor of $3.88 \mu \mathrm{sec} / \mathrm{deg}$ azimuth is remarkably similar to the $3.64 \mu \mathrm{sec} / \mathrm{deg}$ calculated from the CM data (Fig. 8).

The ITD tuning curves (Fig. 12) provide evidence that great horned owls use ongoing-time differences (i.e., phase disparity) to compute ITD. In the central part of IC, neurons were narrowly tuned to frequency (Fig. 12A), and similar response levels occurred at ITDs separated by integral multiples of the periods of tonal stimuli (Fig. 12B). Noise elicited response peaks at ITDs that were separated by multiples of the period of the neuron's best frequency (Fig. 12C). These tuning curves, with multiple ITD peaks, show phase ambiguity and cannot signal a unique ITD. Phase ambiguity was also evident in the response of $\mathrm{ICX}$ ncurons to toncs (Fig. 12E). Thesc cells, however, had broad frequency tuning (Fig. 12D) and had only one ITD peak common to all frequencies (Fig. 12E). With noise, all peaks except this common one were suppressed, resulting in a maximum response to a single ITD (Fig. 12F).

Although ITD appears to be a sufficient cue for azimuth, it was possible that IID might also be used because, in the periphery, IID did vary with azimuth (Fig. 9). We therefore recorded the IID tuning at 63 sites in 3 owls (Fig. 13). Every ICx unit responded only to binaural stimuli and had a nonmonotonic IID tuning curve (Fig. 13A). Most units preferred equal or nearly equal binaural intensities (Fig. 13B). Although there was a weak but significant correlation between best ITD and best IID $(r=0.39 ; p<0.05)$, neurons with preferences for sounds louder in the left or right ear were found in high proportions on both sides of the brain (Fig. 13C). The widths of the IID tuning curves averaged $24 \mathrm{~dB}$ at half-height (Fig. 13D). Thus, a sound would have to be more than $12 \mathrm{~dB}$ louder in one ear to substantially reduce the response of these cells. Because the maximum IID from the CM measurements was only 12.5 dB (Fig. 9), on the basis of IID alone, most ICx units would likely respond well to sound sources in most spatial positions.

We also investigated the effect of varying IID on the ITD tuning of 14 ICx units. All these units responded near maximum at $0 \mathrm{~dB}$ IID. Reliable responses could be obtained at IIDs of both +10 and $-10 \mathrm{~dB}$ for most units. Half the units responded to IIDs of $20 \mathrm{~dB}$ in one or both directions, and 3 units responded to sounds $30 \mathrm{~dB}$ louder in the contralateral ear. Best ITD shifted systematically with IID (Fig. 14), but the magnitude of the shift was only $1.5 \mu \mathrm{sec} / \mathrm{dB}$ IID (linear slope; $r^{2}=0.83$ ). The shifts were in the direction opposite to that expected for time-intensity trading (see Hafter, 1984); that is, best ITD shifted toward the louder ear.

\section{Discussion}

Neurons in ICx in great horned owls have spatially restricted auditory receptive fields and are topographically organized to form a map of azimuthal location. The fields are not bounded in elevation, at least within the frontal hemisphere. Measured at the ears, ITD varies linearly with azimuth at a rate of 3.6
Figure 8. Cochlear microphonic (CM) recording of interaural time disparity (ITD) as a function of azimuth. ITDs were measured at the horizontal meridian. The relationship between ITD and azimuth, especially for the $3 \mathrm{kHz}$ tone, was essentially linear. Both sets of ITDs from noise stimuli could be fit slightly, but not significantly, better with a thirdorder polynomial equation. The ITDs from noise were measured for frequencies from 1.5 to $6 \mathrm{kHz}$ (see Materials and Methods). The difference between the noise and tone data suggest that ITD may be somewhat frequency dependent. For the combined data, both the linear slope (dashed line, $r^{2}=0.954$ ) and the polynomial curve (solid line, $r^{2}$ $=0.963$ ) are shown, although the curvilinear fit is not significantly better than the linear.

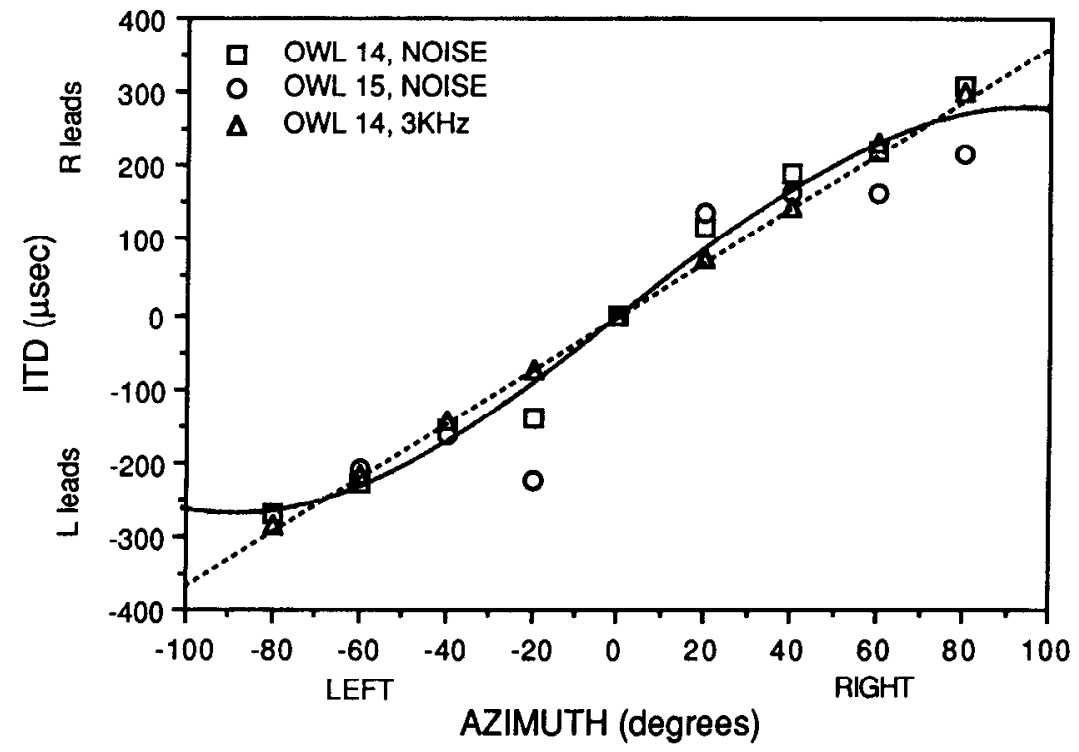


A

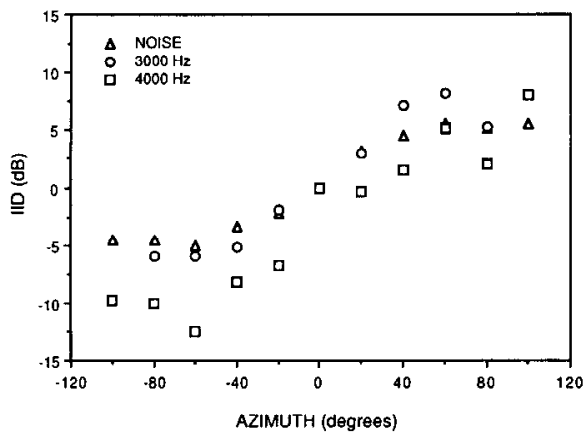

B

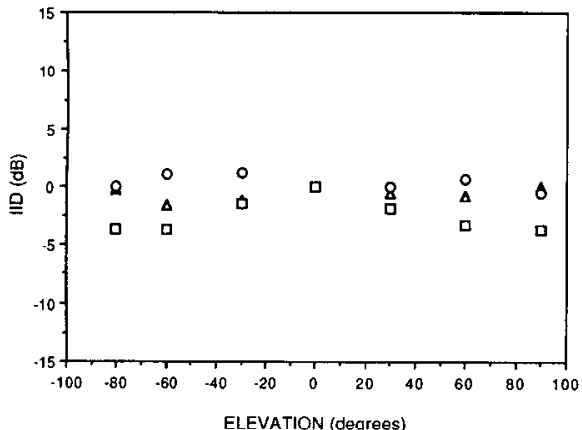

C

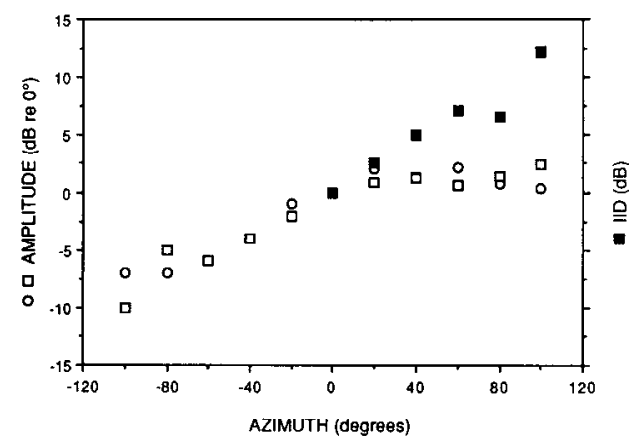

D

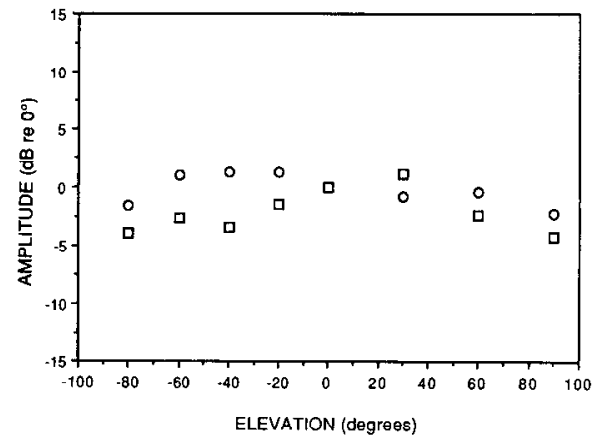

Figure 9. Relationships between IID and azimuth and elevation. For all data, IID or sound amplitude is plotted relative to the value at $0^{\circ}$ azimuth and clevation. $A$ and $B, C M$ data. Sound amplitudes were as follows: $3 \mathrm{kHz}$ at $56 \mathrm{~dB} \mathrm{SPL} ; 4 \mathrm{kHz}$ at $60 \mathrm{~dB}$ SPL; noise at $49 \mathrm{~dB}$ SPL. $C$ and $D$, Probe microphone data. Both 3 and $4 \mathrm{kHz}$ tone were $74 \mathrm{~dB}$ SPL free-field amplitude. The microphone was in the right ear. Symbols for all graphs correspond to the legend in $A$. Filled squares in $C$ are IIDs calculated from the monaural data from the $4 \mathrm{kHz}$ tone and are shown for the right side only. $\mu \mathrm{sec} / \mathrm{deg}$, whereas IID is less than $15 \mathrm{~dB}$ at every location. Neither ITD nor IID vary appreciably with elevation. The ITD tuning of $\mathrm{ICx}$ neurons correlates with receptive field azimuth and also with position in the nucleus. These cells are also sensitive to IID, but most of them prefer nearly equal intensities in the 2 ears.

The absence of elevation sensitivity in ICx neurons does not necessarily imply that great horned owls cannot detect elevation. Humans, for example, use spectral cues to localize sounds in the vertical plane, as opposed to the ITD and IID cues used for azimuth (Blauert, 1983). Similar cues for elevation may be available to these owls and may be processed outside of ICx. We did not detect significant spectral differences in our CM recordings, but we systematically tested only 2 frequencies. Behavioral experiments are necessary to determine this owl's ability to localize sound elevation, as well as to assess its azimuthal acuity.

\section{Comparison with other systems}

The map of azimuth in great horned owls is similar to that in barn owls (Knudsen and Konishi, 1978a, b): Neurons with central receptive fields are found at the rostral pole of $\mathrm{ICX}$, and peripheral, contralateral fields are more caudally located. In the barn owl, fields centered at up to $15^{\circ}$ ipsilateral are found rostromedial in ICx, whereas in the great horned owl, we recorded fields at most $9^{\circ}$ ipsilateral. This difference may reflect a true difference in bilateral overlap; however, it may also be a consequence of the greater dorsoventral thickness of the barn owl's ICx, which provides a larger recording area. In barn owls, stimulus elevation is encoded according to depth in ICx, but elevation sensitivity is lacking in great horned owls.

In both owl species, there is a projection from the spacemapped region of IC to the optic tectum (Fig. 2; Knudsen and Knudsen, 1983). After HRP injections into the tectum of barn owls, ICx neurons are densely labeled. By contrast, ICx cells in the great horned owl were only lightly labeled after similar injections. It should be noted, however, that retrograde labeling patterns depend on which layers of the tectum are injected, and our injections may not have been directly comparable to those in the barn owls. That the different labeling of ICx does reflect a real difference between the 2 species is supported by 2 findings: (1) We were able to evoke a weak auditory response from only one tectal unit in a great horned owl, whereas in barn owls, tectal neurons are quite responsive to sound (Knudsen, 1983). (2) The parvocellular division of nucleus isthmi (IP) showed opposite labeling patterns. In the barn owls, ICx was more densely and reliably labeled than was IP, whereas in the great horned owls, more consistent, denser label was seen in IP.

The azimuthal width of receptive fields in the great horned owl ranged from $15^{\circ}$ to $52^{\circ}$ (mean $=32^{\circ}$ ). This compares with a range of $7^{\circ}-39^{\circ}\left(\right.$ mean $\left.=25^{\circ}\right)$ for the barn owl (Knudsen and Konishi, 1978b). Azimuthal acuity can also be compared using the ITD tuning data from dichotic experiments on the 2 species. For noise stimuli, we found the mean width of ITD peaks at half-height was $72.5 \pm 30.6 \mu \mathrm{sec}$ (mean $\pm \mathrm{SD}, n=81$ ); for barn owls, this width is $51.6 \pm 9.8 \mu \mathrm{sec}(n=25)$. Scaling these widths by $3.88 \mu \mathrm{sec} / \mathrm{deg}$ for the great horned owl and $2.86 \mu \mathrm{sec} / \mathrm{deg}$ for the barn owl (Moiseff and Konishi, 1981a) gives widths of $19^{\circ}$ and $18^{\circ}$, respectively. Thus, the barn owl's temporal acuity is significantly greater than the great horned owl's $(p<0.005$, Student's $t$ test), but spatial resolution in the 2 species is almost the same, a consequence of the great horned owl's larger head and interaural distance.

ICx neurons in barn owls have broad frequency ranges, with best frequencies most often between 6000 and $7000 \mathrm{~Hz}$. In great horned owls, best frequencies are usually between 3500 and $4500 \mathrm{~Hz}$. Better phase resolution, which can in theory be obtained from higher frequencies, might explain the barn owl's greater temporal acuity. In the barn owl, tuning widths do sharp- 
Figure 10. ITD tuning curves at different positions in IC. The ITD tuning curves for noise stimuli (left) are all from a single owl. One tuning curve each from 6 penetrations is shown. In the 3 most anterior penetrations, data were recorded at 2 or more sites, and the narrowest tuning curve was chosen for this illustration. The third and fourth curves from the top are from clusters of 2-3 units; the rest are single units. Each penetration was marked with a lesion, and its position (right) was calculated relative to the anterior and posterior poles of IC. Best ITD increased monotonically with posterior displacement in IC.
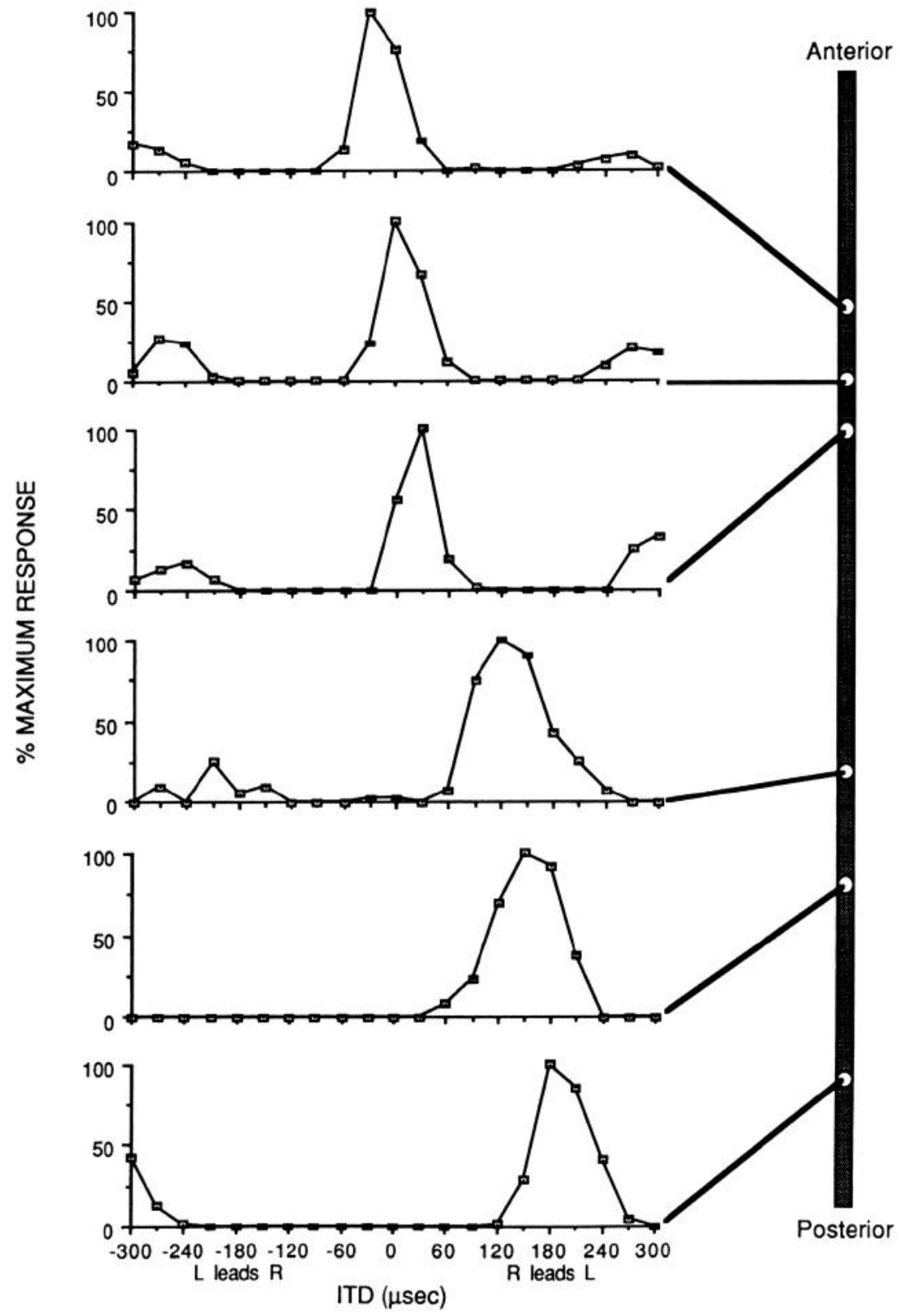

en by an average of $12 \mu \mathrm{sec}$ (about $4^{\circ}$ ) from 3500 to $7000 \mathrm{~Hz}$, although ITD tuning becomes less sharp above $7000 \mathrm{~Hz}$ (Fig. 15 ). But even over the common frequency range for the 2 species $(3300-5200 \mathrm{~Hz})$, the barn owl's ITD tuning is narrower than the great horned owl's, although there is considerable overlap (Fig. 15). In this frequency range, ITD widths averaged $51 \pm$ $12 \mu \mathrm{sec}$ (mean $\pm \mathrm{SD}$ ) in the barn owl and $63 \pm 17 \mu \mathrm{sec}$ in the great horned owl $(t=3.71, p<0.001, d f=108)$. The barn owl's better time resolution must then depend on neuronal mechanisms that sharpen ITD tuning as well as on the use of higher frequencies.

Mammals use interaural phase disparities to localize lowfrequency tones. The maximum frequency at which mammalian neurons are sensitive to ITD varies across species, but the highest best frequency of an ITD selective neuron reported is 3.1 $\mathrm{kHz}$ in the cat (Kuwada and Yin, 1983). Behavioral studies in a variety of mammals indicate that ITD is not used for localization of frequencies greater than about $4 \mathrm{kHz}$ (see Heffner and
Heffner, 1988). In the great horned owl, we found neurons sensitive to interaural phase differences of tones to at least $5.3 \mathrm{kHz}$. This high-frequency phase sensitivity does not approach the barn owl's, which extends to frequencies above $8 \mathrm{kHz}$ (Moiseff and Konishi, 1981a; Sullivan and Konishi, 1984; also Fig. 15). Nevertheless, both owl species are able to extract unique ITD at frequencies where phase ambiguity occurs (Fig. 12; Takahashi and Konishi, 1986; Wagner et al., 1987).

Time-intensity trading is a phenomenon noted in psychophysical studies on auditory localization in humans, and trading ratios of various magnitudes have been reported (see Hafter, 1984). In these studies, when sound intensity is increased in one ear, the apparent displacement of the sound can be compensated by increasing the delay of the louder ear. In the great horned owl, ICx units showed small ITD shifts in the direction opposite to that expected from psychophysical studies (Fig. 14). Little or no effect of IID on ITD has been found in most physiological studies of IC in mammals; however, in a quantitative assessment 


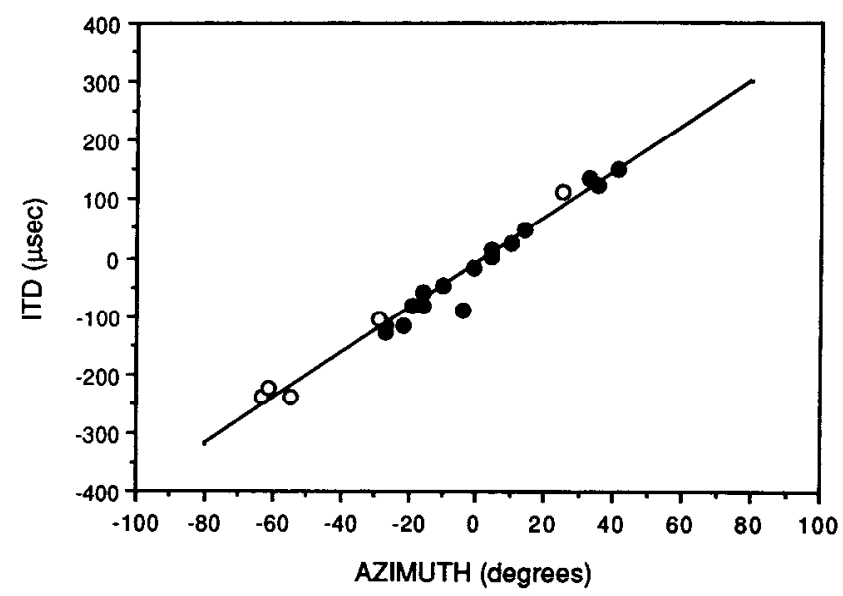

Figure 11. Correlation of best ITD and azimuth of receptive fields. Data are from 17 single units or clusters of $2-4$ units. In order to obtain ITD peaks and spatial receptive fields over a wide range, we used tones as well as noise. Tonal stimuli generate secondary receptive fields (see Fig. $5 B$ ) and secondary ITD peaks (see Fig. $12 E$ ). Filled circles; Primary peaks, elicited by noise; open circles; secondary peaks from tonal stimuli. See text for regression equation.
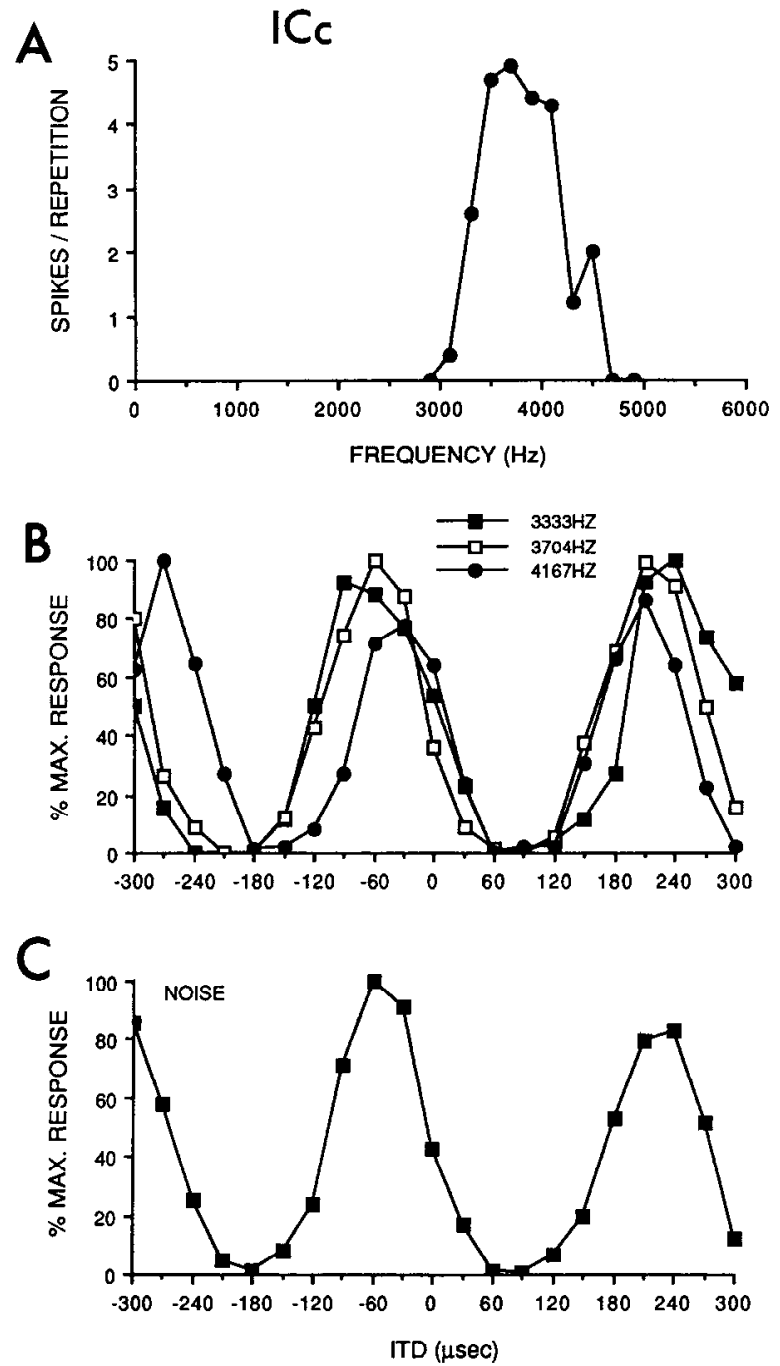

of this question, Yin and Kuwada $(1983,1984)$ found an average shift of $5.8 \mu \mathrm{sec} / \mathrm{dB}$ IID in the cat. This shift was also towards the louder ear rather than away from it. The ITD tuning of ICx neurons in barn owls is not very sensitive to changes in IID (Moiseff and Konishi, 1981a; Takahashi et al., 1984), but in this species also, when ITD shifts do occur, they are towards the louder ear ( $T$. Takahashi, personal communication; and see figure 4, Takahashi et al., 1984). Changing IID shifts ITD similarly in the optic tectum of the barn owl (Olsen et al., 1989).

In a physiological study of 3 diurnal raptors, Calford et al. (1985) found that units in ICX (or nMLDI in their nomenclature) also had broader frequency ranges and were more spatially selective than were units in ICc (central nMLD). These spatially selective units, however, had distinct medial boundaries only. No topographic arrangement was found beyond a weak tendency for units with more lateral receptive fields to be more superficial in the nucleus. As only free-field stimuli were used, it is not known whether the medial boundaries were derived from time or intensity cues. The authors suggested that a pressure-gradient mechanism (see below) could make intensity information available in the frequency range used by these birds $(<5000 \mathrm{~Hz})$. Their data, however, do not exclude the possibility that ITD
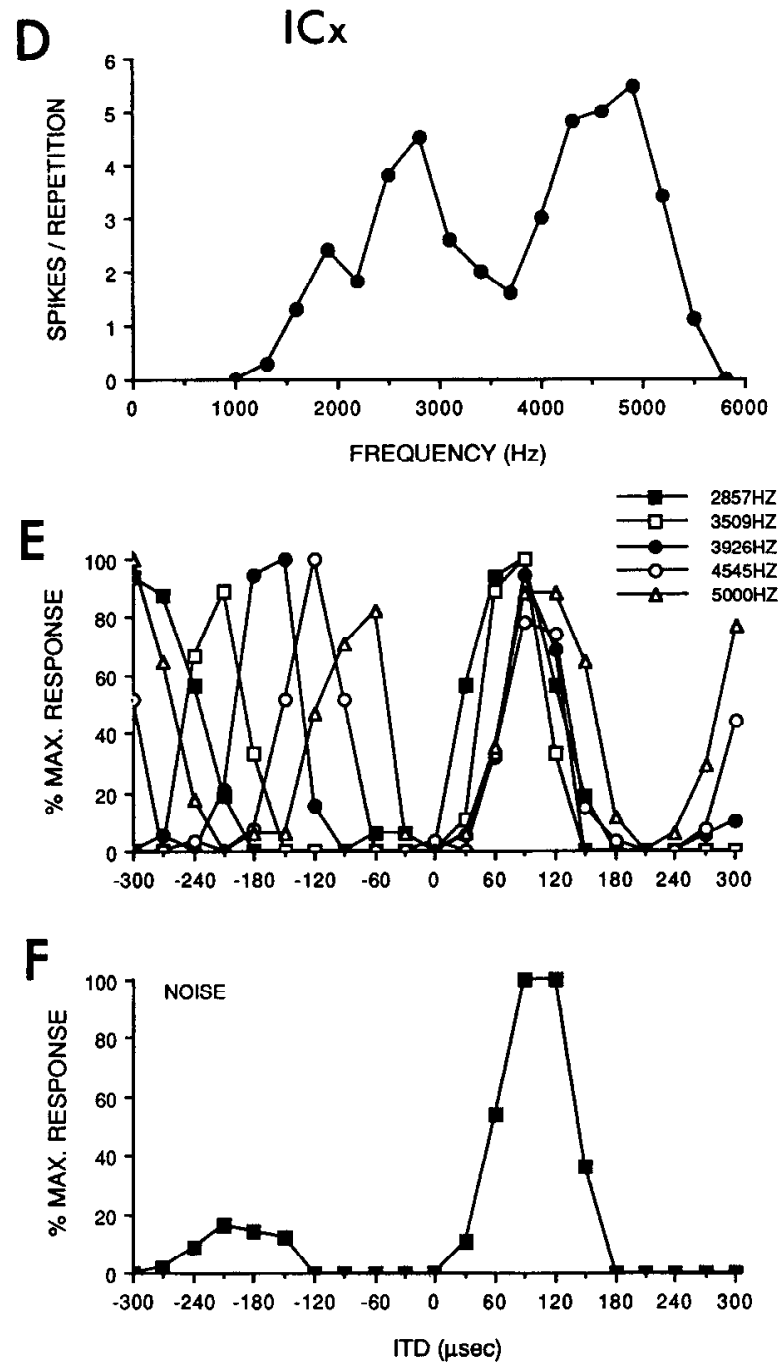

Figure 12. Comparison of frequency and ITD tuning in ICc and ICx. $A-C$, Unit recorded in ICc. $A$, Response to changing frequency. $B$, ITD tuning at 3 different frequencies. The peaks in the ITD response curves are at integral multiples of the periods. $C$, ITD tuning in response to a noise stimulus. $D-F$, Response of a unit recorded in ICx. Each plot corresponds to those in $A-C$ for the ICc unit. In ICx, a noise stimulus elicits only one large peak $(F)$. 
A

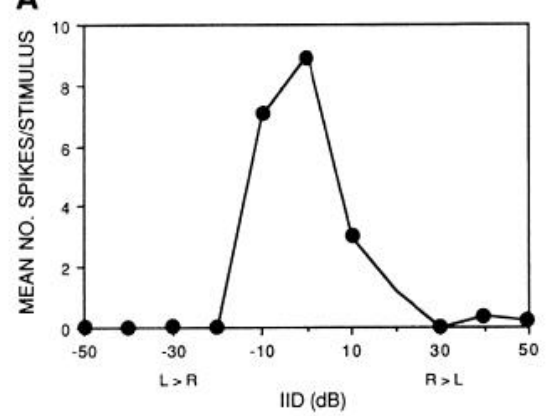

Figure 13. IID tuning to dichotic noise stimulation. $A$, Example of an IID tuning curve of a unit of ICx. The average binaural amplitude at each IID was 30 dB SPL. $B$, Distribution of best IIDs. Data are from both single units and clusters of 2-4 units recorded from both sides of the brains of 3 owls. $C$, Correlation of best ITD and best IID. Open squares, units recorded in right IC; filled circles, units recorded in left IC. Best ITD and IID are weakly correlated ( $r$ $=0.39$ ), but there are high incidences of both negative (left louder) and positive (right louder) best IIDs at both negative and positive best ITDs. $D$, Distribution of widths of IID tuning curves. The widths were measured at the half-height of the tuning curves. IID tuning was determined at the best ITD for each unit.
C

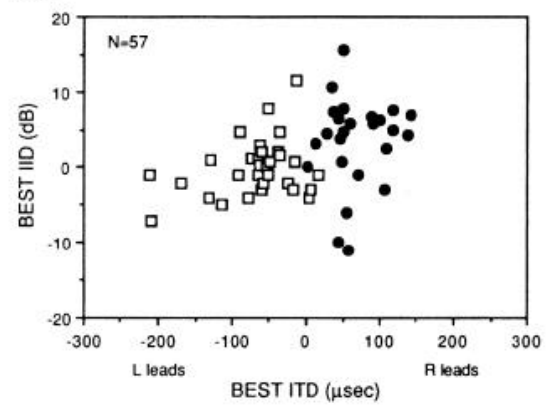

B

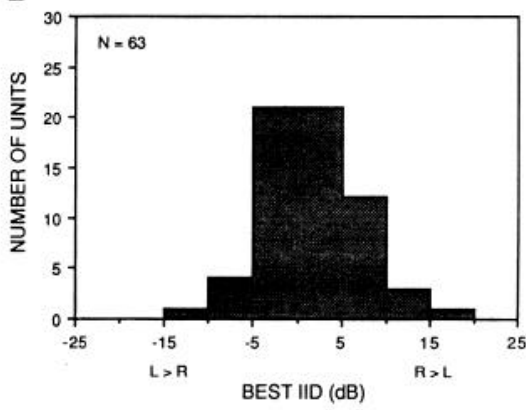

D

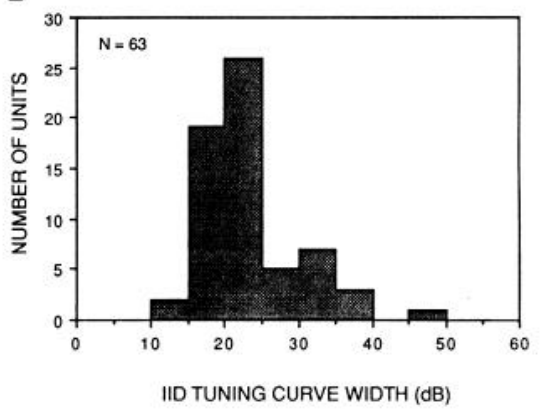

information may be used, because broad receptive fields with no lateral boundaries could result from broad ITD tuning.

In many bird species, there is evidence that the interaural canal (an air cavity connecting the 2 ears) allows the ears to function as pressure-gradient receivers (Coles et al., 1980; Hill et al., 1980; Rosowski and Saunders, 1980; Calford, 1988). This mechanism can generate much larger interaural amplitude differences than would be expected from sound shadowing alone. In barn owls, when sound is delivered through earphones, sound transmitted through the interaural canal is attenuated by more than $40 \mathrm{~dB}$ for the range of frequencies $(5-8 \mathrm{kHz})$ to which space-specific neurons are most responsive (Moiseff and Konishi, 1981b). Free-field measurements, however, suggest that the canal may enhance directionality (Coles and Guppy, 1988). Space-specific neurons in great horned owls respond to lower frequencies than those in the barn owl, but in this species also, there appears to be little transmission through the interaural canal at 3 and $4 \mathrm{kHz}$. If a pressure gradient were used, monaural sound intensity or IID at some spatial positions should differ between the $\mathrm{CM}$ recordings and the microphone measurements taken outside the tympanic membrane. However, the data we obtained with both methods were essentially the same (Fig. 9). We also measured interaural transmission directly by stimulating with a $3 \mathrm{kHz}$ tone through an earphone in the left ear while recording the $\mathrm{CM}$ potential in the right ear with its earphone removed. The $\mathrm{CM}$ response was measurable only when the sound was loud enough (about $80 \mathrm{~dB} \mathrm{SPL}$ ) to be heard about $10 \mathrm{~cm}$ from the owl's head and could have reached the right ear through the air. The amplitude in the right ear, calculated from the $\mathrm{CM}$ response, was $30 \mathrm{~dB}$ less than in the left ear.

Although ICx units in great horned owls appear to rely mainly on ITD to encode azimuth, they nevertheless have nonmonotonic IID tuning of the sort called " $00 / F$ " found in cat superior colliculus (Wise and Irvine, 1985). That is, they do not respond to monaural stimuli and are facilitated by binaural stimuli. ICx and tectal units in the barn owl have IID tuning curves of this same shape (Moiseff and Konishi, 1983; Takahashi et al., 1984; Olsen et al., 1989). In the barn owl tectum, the mean $50 \%$ widths of IID tuning curves is $15.4 \mathrm{~dB}$, almost $10 \mathrm{~dB}$ narrower than in the great horned owl. Furthermore, IIDs in the barn owl range from at least $19 \mathrm{~dB}$ left louder to $17 \mathrm{~dB}$ right louder, and IID is strongly correlated with best elevation. In the great horned owl, on the other hand, the functional significance of IID tuning is unclear. The ears are both broadly directional, and therefore, it seems unlikely that the IID of a sound from any position would fall outside the binaurally facilitated part of the IID tuning curves. Nevertheless, we did find a weak correlation between best IID and best ITD, so IID may be a supplementary cue for azimuth. In addition, there are 2 reasons to suspect that IID tuning could be sharper and more strongly correlated with azimuth than indicated by our data. First, free-field IIDs are frequency dependent (Fig. 9), but in our dichotic stimuli, the IID of all frequencies are the same. In the barn owl, it has been shown that the IID tuning of tectal units improves if dichotic stimuli mimic the frequency-dependence of free-field stimuli (Esterly and Knudsen, 1987). Second, for some units small differences in the ITD at which IID data are collected might alter measurements of best IID. For example, for the unit shown in Figure $14 A$, if the ITD used were just $15 \mu \mathrm{sec}$ more left-leading than the peak ITD, best IID would most likely shift to the left. Although we recorded all IID tuning at the ITD that had given the best response, these ITDs are only within $30 \mu \mathrm{sec}$ of the mean best ITDs calculated later from the ITD tuning curves.

Another completely different role for IID tuning might be to prevent $\mathrm{ICx}$ neurons from firing to spontaneous activity generated in monaural nuclei afferent to IC. Finally, the fact that neurons in ICx respond only to binaural stimuli might be a consequence of their ITD tuning. That is, monaural stimuli, by definition, cannot have optimal ITDs. It should be noted, however, that neurons in ICc do respond to some monaural stimuli even when they are sharply tuned for ITD and give no response at nonoptimal ITDs (unpublished observations). 


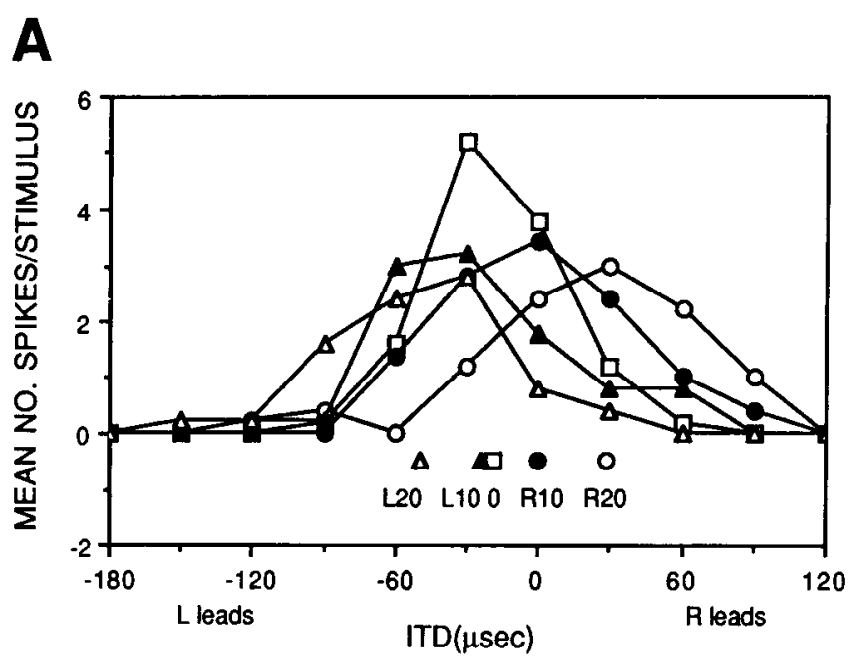

B

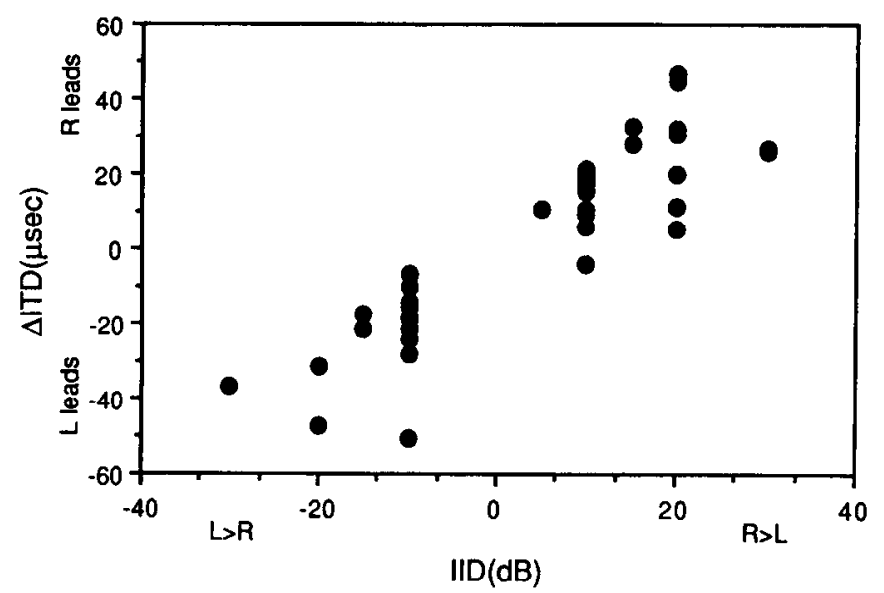

Figure 14. A, Example of the effect of varying IID on the ITD tuning of a single unit. The symbols below the tuning curves mark ITD peak and are also a key for the curves; e.g., R20 indicates $20 \mathrm{~dB}$ right louder than left. $B$, Dependence of ITD tuning on IID. Data are from 14 units, 10 from the right ICx and 4 from the left. For each unit 0 ITD is the best ITD for equal sound levels at the 2 ears ( 0 IID).

\section{Evolution}

Many owl species besides barn owls have bilaterally asymmetrical ears. Morphological and phylogenetic evidence indicate that ear asymmetry evolved independently in at least 5 lines of owls (Norberg, 1977). Although the great horned owl's ears are symmetrical, in other species of the genus $B u b o$ the right ear has a somewhat larger ear opening than the left ear. Furthermore, $B u b o$ is probably closely related to several other genera in which some species have highly specialized ear asymmetries (Norberg, 1977; S. Coats, personal communication). Thus, the great horned owl's brain organization does not necessarily represent that of a primitive, symmetrical owl ancestor. The IID tuning we found in the great horned owl may reflect its close relationship with other owls that have asymmetrical ears. In even the simplest form of asymmetry found in some of the great horned owl's close relatives-one ear with a longer opening than the other-IID could encode some information about stimulus elevation. If the smaller ear is more directional than the larger ear, sound from some locations would be significantly louder in the larger ear. Even if all IID peaks were near $0 \mathrm{~dB}$, receptive fields might be restricted to a single band or hemifield of elevations.

If, on the other hand, the response properties of neurons in the great horned owl are typical of all symmetrical owls, there is an intriguing possibility that IID tuning in ICx might preadapt this nucleus to encode stimulus elevation in owls with asymmetrical ears. If the extensive data from the barn owl can be taken as representative of other owls with asymmetrical ears, 2 neural adaptations are necessary to exploit a change in external ear morphology: (1) an increased sensitivity to high frequencies is probably required because IIDs are greater in the vertical plane for high frequencies (Coles and Guppy, 1988; Moiseff, 1989b). In fact, data from at least 15 species of owls suggest that the ability to hear well at frequencies above $6 \mathrm{kHz}$ does correlate with ear asymmetry (Trainer, 1946; Schwartzkopff, 1962; Dijk, 1973; Calford, 1988; Wise et al. 1988; S. Volman, unpublished observations). (2) The range of best IIDs in ICx must cover the range of IIDs generated in the periphery.

In barn owls, the pathways that encode ITD and IID are separate, and they converge only in a portion of ICc and in ICX. Nonmonotonic IID tuning is unique to the space-specific neurons in ICx (Moiseff and Konishi, 1983; Takahashi et al., 1984). If the similar convergence of these 2 pathways in the great horned owl does represent the primitive condition, it would provide the neural substrate necessary to take advantage of ear asymmetry and may partially account for the relative ease with which such asymmetry, in a variety of forms, has arisen among the owls. Further studies on other species of owls with symmetrical and asymmetrical ears will be required to resolve the phylogenetic pattern of ITD and IID tuning in ICX and their relative contributions to sound localization.
GREAT HORNED OWL

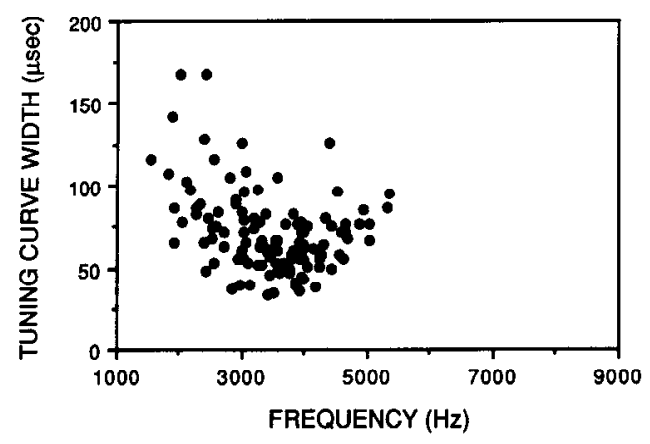

Figure 15. Comparison of ITD tuning for ICx units from great horned and barn owls. For both species, many of the units contributed data at more than one frequency. In all, 51 single units from great horned owls and 30 from barn owls are represented. See text for quantitative comparisons between the 2 species. (The widths for barn owls were measured on tuning curves recorded by T. Takahashi.) 


\section{References}

Aitkin, L. M., J. D. Pettigrew, M. B. Calford, S. C. Phillips, and L. Z. Wise (1985) Representation of stimulus azimuth by low-frequency neurons in inferior colliculus of the cat. J. Neurophysiol. 53: 43-59.

Blauert, J. (1983) Spatial Hearing. The Psychophysics of Human Sound Localization, MIT Press, Cambridge, MA.

Calford, M. B. (1988) Constraints on the coding of sound frequency imposed by the avian interaural canal. J. Comp. Physiol. A 162: 491502 .

Calford, M. B., L. Z. Wise, and J. D. Pettigrew (1985) Coding of sound location and frequency in the auditory midbrain of diurnal birds of prey, families Accipitridae and Falconidae. J. Comp. Physiol. A 157. 149-160.

Coles, R. B., and A. Guppy (1988) Directional hearing in the barn owl (Tyto alba). J. Comp. Physiol. A 163: 117-133.

Coles, R. B., D. B. Lewis, K. G. Hill, M. E. Hutchings, and D. M. Gower (1980) Directional hearing in the Japanese quail (Coturnix coturnix japonica) II. Cochlear physiology. J. Exp. Biol. 86: 153-170.

Dijk, T. van (1973) A comparative study of hearing in owls of the family Stigidae. Neth. J. Zool. 23: 131-167.

Esterly, S. D., and E. I. Knudsen (1987) Tuning for interaural difference cues varies with frequency for space-specific neurons in the owl's optic tectum. Soc. Neurosci. Abstr. 13: 1468

Fuzessery, Z. M., and G. D. Pollak (1985) Determinants of sound location selectivity in bat inferior colliculus: A combined dichotic and free-field stimulation study. J. Neurophysiol. 54: 757-781.

Hafter, E. (1984) Spatial hearing and the duplex theory: How viable is the model? In Dynamic Aspects of Neocortical Function, G. M. Edelman, W. E. Gall, and W. M. Cowan, eds. pp. 425-448, Wiley, New York.

Heffner, R. S., and H. E. Heffner (1987) Localization of noise, use of binaural cues, and a description of the superior olivary complex in the smallest carnivore, the least weasel (Mustela nivalis). Behav. Neurosci. 101: 701-708.

Heffner, R. S., and H. E. Heffner (1988) Sound localization and use of binaural cues by the gerbil (Meriones unguiculatus). Behav. Neurosci. 102: 422-428.

Hill, K. G., D. B. Lewis, M. E. Hutchings, and R. B. Coles (1980) Directional hearing in the Japanese quail (Coturnix coturnix japonica). I. Acoustic properties of the auditory system. J. Exp. Biol. 86: 135-151.

Katz, L. C., A. Burkhalter, and W. J. Dreyer (1984) Fluorescent latex micropheres as a retrograde neuronal marker for in vivo and in vitro studies of visual cortex. Nature 310: 98-100.

Kelso, L. (1940) Variation of the external ear-opening in the Strigidae. Wilson Bull. 52: 4-29.

King, A. J., and M. E. Hutchings (1987) Spatial response properties of acoustically responsive neurons in the superior colliculus of the ferret: A map of auditory space. J. Neurophysiol. 57: 596-624.

King, A. J., and A. R. Palmer (1983) Cells responsive to free-field auditory stimuli in guinea-pig superior colliculus: Distribution and response properties. J. Physiol. (Lond.) 342: 361-381.

Knudsen, E. I. (1983) Subdivisions of the inferior colliculus in the barn owl (Tyto alba). J. Comp. Neur. 218: 174-186.

Knudsen, E. I., and P. F. Knudsen (1983) Space-mapped auditory projections from the inferior colliculus to the optic tectum in the barn owl (Tyto alba). J. Comp. Neur. 218: 187-196.

Knudsen, E. I., and M. Konishi (1978a) A neural map of auditory space in the owl. Science 200:795-797.

Knudsen, E. I., and M. Konishi (1978b) Space and frequency are represented separately in the auditory midbrain of the owl. J. Neurophysiol. 41: 870-884.

Knudsen, E. I., and M. Konishi (1979) Mechanisms of sound localization in the barn owl (Tyto alba). I. Comp. Physiol. 133: 13-21.

Konishi, M. (1973) How the owl tracks its prey. Am. Sci. 61: 414424.

Kuwada, S., and T. C. T. Yin (1983) Binaural interaction in lowfrequency neurons in inferior colliculus of the cat. I. Effects of long interaural delays, intensity, and repetition rate on interaural delay function. J. Neurophysiol. 50: 981-999.

Mesulam, M.-M. (1978) Tetramethyl benzidine for horseradish peroxidase neurochemistry: A non-carcinogenic blue reaction product with superior sensitivity for visualizing neural afferents and efferents. J. Histochem. Cytochem. 26: 106-117.
Middlebrooks, J. C., and E. I. Knudsen (1984) A neural code for auditory space in the cat's superior colliculus. J. Neurosci. 4: 26212634.

Moiseff, M. (1989a) Bi-coordinate sound localization by the barn owl. J. Comp. Physiol. 164: 629-636.

Moiseff, M. (1989b) Binaural disparity cues available to the barn owl for sound localization. J. Comp. Physiol. 164: 637-644.

Moiseff, A., and M. Konishi (1981a) Neuronal and behavioral sensitivity to binaural time differences in the barn owl. J. Neurosci. 1: $40-48$.

Moiseff, A., and M. Konishi (1981b) The owl's interaural pathway is not involved in sound localization. J. Comp. Physiol. A 144: 299304.

Moiseff, A., and M. Konishi (1983) Binaural characteristics of units in the owl's brainstem auditory pathway: Precursors of restricted spatial receptive fields. J. Neurosci. 3: 2553-2562.

Norberg, R. $\AA$. (1977) Occurrence and independent evolution of bilateral ear asymmetry in owls and implications on owl taxonomy. Phil. Trans. R. Soc. London [Biol.] 280: 375-408.

Norberg, R. $\AA$. (1978) Skull asymmetry, ear structure and function, and auditory localization in Tengmalm's owl, Aegolius funerus (Linne). Phil. Trans. R. Soc. London [Biol.] 282: 325-410.

Olsen, J. F., E. I. Knudsen, and S. D. Esterly (1989) Neural maps of interaural time and intensity differences in the optic tectum of the barn owl. J. Neurosci. 9: 2591-2605.

Payne, R. S. (1971) Acoustic location of prey by barn owls (Tyto alba). J. Exp. Biol. 54: 535-573.

Pumphrey, R. J. (1948) The sense organs of birds. Ibis 90: 170-199.

Ramón y Cajal, S. (1972) Histologie du Systeme Nerveux de l'Homme et des Vertebres, Tome 1, Instituto Ramón y Cajal, Madrid.

Rosowski, J. J., and J. C. Saunders (1980) Sound transmission through the avian interaural pathway. J. Comp. Physiol. A 136: 183-190.

Schwartzkopff, J. (1962) Zur frage des richlungshörens von eulen (striges). Z. vergl. Physiol. 45: 570-580.

Sullivan, W. E., and M. Konishi (1984) Segregation of stimulus phase and intensity coding in the cochlear nucleus of the barn owl. J. Neurosci. 4: 1787-1799.

Takahashi, T., and M. Konishi (1986) Selectivity for interaural time difference in the owl's midbrain. J. Neurosci. 6: 3413-3422.

Takahashi, T., A. Moiseff, and M. Konishi (1984) Time and intensity cues are processed independently in the auditory system of the owl. J. Neurosci. 4: 1781-1786.

Takahashi, T., C. E. Carr, N. Brecha, and M. Konishi (1987) Calcium binding protein-like immunoreactivity labels the terminal field of nucleus laminaris of the barn owl. J. Neurosci. 7: 1843-1856.

Trainer, J. E. (1946) The Auditory Acuity of Certain Birds. Ph.D. dissertation, Cornell University, Ithaca, New York.

Wagner, H., T. Takahashi, and M. Konishi (1987) Representation of interaural time differences in the central nucleus of the barn owl's inferior colliculus. J. Neurosci. 7: 3105-3116.

Wenstrup, J. J., L. S. Ross, and G. D. Pollak (1986) Binaural response organization within a frequency-band representation of the inferior colliculus: Implications for sound localization. J. Neurosci. 6: 962973.

Wise, L. Z., and D. R. F. Irvine (1985) Topographic organization of interaural intensity difference sensitivity in deep layers of cat superior colliculus: Implications for auditory spatial representation. J. Neurophysiol. 54: 185-211.

Wise, L. Z., B. J. Frost, and S. W. Shaver (1988) The representation of sound frequency and space in the midbrain of the saw-whet owl (Aegolius acadicus). Soc. Neurosci. Abstr. 14: 1095.

Wong, D. (1984) Spatial tuning of auditory neurons in the superior colliculus of the echolocating bat, Myotis lucifugas. Hear. Res. 16: 261-270.

Yin, T. C. T., and S. Kuwada (1983) Binaural interaction in lowfrequency neurons in inferior colliculus of the cat. III. Effects of changing frequency. J. Neurophysiol. 50: 1020-1042.

Yin, T. C. T., and S. Kuwada (1984) Neuronal mechanisms of binaural interactions. In Dynamic Aspects of Neocortical Function, G. M. Edelman, W. E. Gall, and W. M. Cowan, eds. pp. 263-313, Wiley, New York.

Yin, T. C. T., J. C. K. Chan, and S. Kuwada (1983) Characteristic delays and their topographical distribution in the inferior colliculus of the cat. In Mechanisms of Hearing, W. R. Webster and L. M. Aitkin, eds., Monash University Press, Monash. 